\title{
The language and body language of political communication: Investigating the effects of the verbal versus the visual in televised gubernatorial debates
}

\author{
Nicole Bernadette Fernandes \\ West Virginia University
}

Follow this and additional works at: https://researchrepository.wvu.edu/etd

\section{Recommended Citation}

Fernandes, Nicole Bernadette, "The language and body language of political communication: Investigating the effects of the verbal versus the visual in televised gubernatorial debates" (2010). Graduate Theses, Dissertations, and Problem Reports. 3298.

https://researchrepository.wvu.edu/etd/3298

This Thesis is protected by copyright and/or related rights. It has been brought to you by the The Research Repository @ WVU with permission from the rights-holder(s). You are free to use this Thesis in any way that is permitted by the copyright and related rights legislation that applies to your use. For other uses you must obtain permission from the rights-holder(s) directly, unless additional rights are indicated by a Creative Commons license in the record and/ or on the work itself. This Thesis has been accepted for inclusion in WVU Graduate Theses, Dissertations, and Problem Reports collection by an authorized administrator of The Research Repository @ WVU. For more information, please contact researchrepository@mail.wvu.edu. 
THE LANGUAGE AND BODY LANGUAGE OF POLITICAL COMMUNICATION:

INVESTIGATING THE EFFECTS OF THE VERBAL VERSUS THE VISUAL IN TELEVISED

GUBERNATORIAL DEBATES

\author{
Nicole Bernadette Fernandes
}

\begin{abstract}
Thesis submitted to the
Perley Isaac Reed School of Journalism

at West Virginia University

in partial fulfillment of the requirements

for the degree of
\end{abstract}

Master of Science

in

Journalism

\author{
Approved by \\ Jensen Moore, Ph.D., Committee Chairperson \\ Sara Magee, Ph.D. \\ Steve Urbanski, Ph.D. \\ Michael Lastinger, Ph.D. \\ The Perley Isaac Reed School of Journalism
}

Morgantown, West Virginia
2010

Keywords: political communication; social judgment theory; heuristic-systematic processing; televised debates; gubernatorial campaigns; verbal and visual effects on attitudes and behaviors 


\section{ABSTRACT \\ The Language and Body Language of Political Communication: Investigating the Effects of the Verbal versus the Visual in Televised Gubernatorial Debates}

\section{Nicole Bernadette Fernandes}

This experimental study investigated the effects of the verbal and visual elements of a series of United States televised gubernatorial debates than took place between the $2006-2009$ election years. Guided by the Social Judgment Theory and the Heuristic-Systematic Model, a series of 16 debate clips were shown to participants to gauge their attitudes and voting intentions toward the candidates running for office. The hypotheses predicted a correlation between viewers' level of interest in the topics discussed and their attitudes (positive or negative) toward the candidates, as well as their intentions to vote for them. Findings indicated that regardless of the content of the debate topics, participants had the most positive attitudes toward and the greatest intentions to vote for the LowVerbal/HighVisual gubernatorial candidates. While viewers also expressed positive attitudes toward the HighVerbal/LowVisual debaters, results indicated that they were still far more inclined to vote for the LowVerbal/HighVisual candidates. The topics discussed by the debaters elicited fairly neutral responses from the viewers. This suggests that they did not have much influence on viewers' intentions to vote for certain candidates. 


\section{Acknowledgments}

I would first like to thank Dean Maryanne Reed and the faculty and staff at the West Virginia University Perley Isaac Reed School of Journalism for their support and guidance throughout my undergraduate and graduate years at WVU. They provided me with the skills, knowledge and confidence to find my way as a new researcher in the world of mass media studies.

I would like to thank my committee chair Assistant Professor Jensen Moore-Copple. She went above and beyond the call of duty to help me with every aspect of my research and I am very grateful for all the time and resources she invested in my project. A special thank you goes out to the other three members of my thesis committee: Assistant Professor Steve Urbanski, who encouraged me to pursue my interest in political communication; Assistant Professor Sara Magee, who helped me contact various broadcast stations to obtain video footage, and Associate Provost of International Academic Affairs Michael Lastinger who offered valuable insight into my topic. Each member of my committee served as a mentor and friend and constantly provided me with encouragement, guidance and excellent resources that allowed this research project to be possible.

I am especially grateful to my parents, Ronald and Rose-Marie Fernandes, for their love and encouragement throughout my undergraduate and graduate years. They have made personal sacrifices to support my educational endeavors and make it possible for me to pursue my goals.

Thank you also to my best friend, Ivan Racadag, for being my support system and always understanding of the demands and stress of graduate school. I also thank him for all his technical assistance in developing, editing and displaying the video clips that were used during the pre-test and experimental procedures.

I would also like to thank the following individuals who assisted me in various important ways with this research project: James Ford, the news production manager at WRAL-TV/Capitol 
Broadcasting Company in North Carolina, for providing me with archived debate footage; School of Journalism Final Cut Pro Instructor Stephen W. Butera; School of Journalism Final Cut Pro student Corey Preece; School of Journalism Technology Coordinator Mike Starling; School of Journalism student worker Brandon Radcliffe, and Jennifer Kowalewski, Ph.D., assistant professor at Texas Christian University.

Finally, thank you to all the 179 WVU School of Journalism students who participated in my experiment and provided me with valuable feedback, and a special thank you to all the professors and instructors who helped me obtain participants for my study. 
Table of Contents

ABSTRACT ........................................................................................................ii

ACKNOWLEDGEMENTS ................................................................................. iii

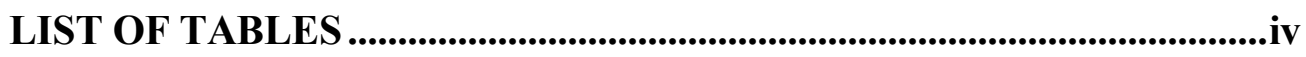

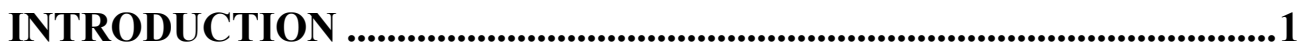

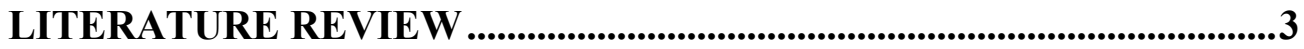

THEORETICAL FRAMEWORK ..................................................................10

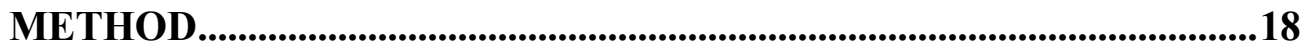

FINDINGS/RESULTS .............................................................................31

DISCUSSION

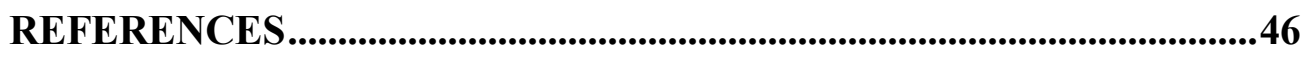

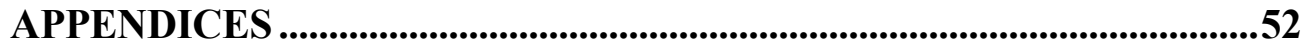




\section{LIST OF TABLES}

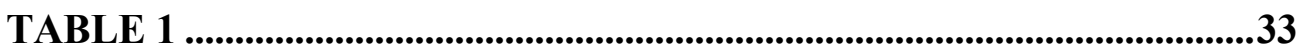

TABLE 2 ....................................................................................................................334

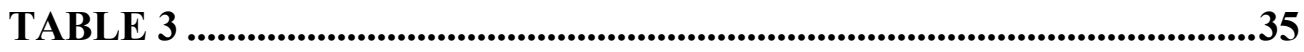

TABLE 4 ........................................................................................................36

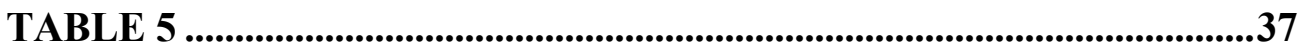




\section{INTRODUCTION}

Televised debates are a public communication staple in contemporary United States political campaigns and an integral part of the campaign landscape. In both national and state political campaigns, televised debates attract larger and more diverse audiences than any other communication form (An \& Pfau, 2004). No other event is so interwoven within the foundational principles of a democracy as an open debate in which candidates have the opportunity to speak directly to voters and voters have the opportunity to listen and compare their arguments. The televised presidential debates in the United States rank among the most watched and most talked about events of a campaign (Blais \& Perrella, 2008).

Television is a visual medium that highlights nonverbal behaviors like scowling, fidgeting, and slouching and has a strong effect on perceptions of a candidate's image (Seiter, Weger, Kinzer, \& Jensen, 2009). Political candidates have to endure an intense level of scrutiny when they campaign and debate on television. Television's intimate nature dictates that performers, in politics or otherwise, have to be more attentive to certain visual cues and behaviors that previously might not have crossed the threshold of significance. In its early analysis of television's political applications, the press claimed that the medium's special intimacy would foster a new relationship between citizens on one hand and office-seekers on the other. This quality of intimacy, derived from the nature of the close-up camera shot, makes it impossible for the speaker to be remote from the audience. A gesture or expression that might have gone unnoticed on stage at a large public gathering can be magnified on a television screen. While television could help win votes for one candidate, it could be dangerous for another if it captures false emotions or overplays small gestures into bothersome habits (Baird, 2003).

Previous research has shown that televised debates prompt viewers to choose the candidate 
with the more appealing and magnetic personality in speaking before the television cameras, rather than the candidate who shares their regional, religious and social affiliations (Reynolds, 1968). According to Baird (2003), television viewers instinctively take into account how a performer looks, how he moves about the podium, and how he appears as a person. The candidate is judged on his appearance, smiles and gestures, and all these features combine with his voice to complete the transmission of personality. Televised debaters incorporate a dual strategy of highlighting issue differences while also emphasizing positive self-images. Issue and image evaluation work together because debate viewers make judgments about those image traits based on the strategies the debaters employ, their issue choices, their demeanors, their willingness to address the questions directly, and the manner in which they attack their opponents (McKinney \& Carlin, 2004).

According to Lang (1987) televised debates have become an integral part of the political scenario and an important factor in campaign strategy. She describes the practice of televised debates as follows:

It is the only form of electoral propaganda that forces the viewers to expose themselves to both candidates in order to judge one of them. Further, because the candidates have to be cognizant of the large numbers of supporters out there who may be judging their every word and gesture, the rhetoric of televised debates tends to avoid what is dangerously controversial while stressing the commonalities that unite all citizens in the pursuit of the common good (p. 212).

Over the years, televised debates have become more like entertainment shows than welldeveloped and significant discussions of vital issues between candidates (Highlander \& Watkins, 1962). According to Baird (2003), a photogenic candidate or official will make an infinitely better impression on his audience than an overweight, unsightly, or over-age candidate or official. This is because televised debates portray political candidates in certain ways, allowing viewers to observe their minutest details, from twitches and worry lines, to coughs and scowls. A great deal of study has been devoted to televised presidential debates, but not much research has been done to 
examine the existence of a similar trend on the gubernatorial level. The following research study will first examine the existing literature and its findings regarding televised debates using social judgment theory and the heuristic model of persuasion as theoretical frameworks. Specifically, this study aims to investigate the verbal versus visual elements of televised debates and how they influence viewers' attitudes and voting behaviors.

\section{LITERATURE REVIEW}

\section{The "Great Debates" of 1960}

Although various types of political debates have occurred in the United States since the $18^{\text {th }}$ century, when the televised meeting of presidential candidates John F. Kennedy and Richard M. Nixon occurred in 1960, it was viewed as an innovation in campaign communication (McKinney $\&$ Carlin, 2004). The "Great Debates" changed the media environment of presidential campaigns in the United States. For the first time, Americans were able to witness as two presidential candidates debated their policies in a face-to-face encounter on television screens in their own homes. Public interest in the debates centered on what type of lighting would be used, if make-up would be permitted, and whether the use of notes would be allowed (Boorstin, 1961). Hence, the "Great Debates" were more like television shows than forums where political candidates could discuss the issues most important to their constituents (Highlander \& Watkins, 1962). According to Boorstin (1961), "the drama of the event was mostly specious or at least had an extremely ambiguous relevance to the main but forgotten issue: which participant was better qualified for the Presidency" (p. 42).

Television coverage of the "Great Debates" played a pivotal role in deciding whether Kennedy or Nixon won the 1960 election. During the first televised debate, Kennedy's main task was to ease misgivings about his inexperience and turn his Catholicism from a liability into an 
asset. When Kennedy initially began considering the presidency in the late 1950s, no Catholic had led a national ticket since 1928, when Albert Smith, the governor of New York was defeated by Herbert Hoover, his Republican opponent. Thirty-two years later, Americans were still wary about electing a young, Catholic president to the highest office in the country (Lang, 1987). However, by the time Kennedy took office most Americans were ready to give him the benefit of the doubt. According to Lang (1987) this change in opinion was in a large part due to the charismatic and presidential image Kennedy projected over television. Lang (1987) stated, “a strong case can be made that without the televised debates in 1960, Kennedy would not have been elected and the course of history would have been changed" (p. 211).

The size of the viewing audience for the Kennedy-Nixon appearances played a decisive role in awarding Kennedy the first debate victory. The audience for the first debate held on September 26, 1960 was estimated at 73.5 million, the largest audience ever addressed by a political candidate. Each of the four debates was reported and commented on by 15 regular radio and television news broadcasts. In addition, a Roper survey conducted close to the 1960 campaign indicated that 52 percent of respondents received their election news from television while only 34 percent relied on the radio. A greater percentage of Americans viewed the debate on television than listened to it on the radio and this could explain why most Americans believed Kennedy emerged as the winner of the first debate (Kane, 1966).

Nixon and Kennedy's contrasting debate styles have also helped researchers identify why viewers awarded the first debate victory to Kennedy. Nixon was much more controlled and traditional in his manner of presentation, while Kennedy's style and delivery reinforced the image of vitality he presented. While Nixon's delivery was slow and conversational, Kennedy's head was tilted back, his hand occasionally chopped at the camera, and he never spoke at fewer than 185 
words a minute, enhancing the impression of vigor. Even though Nixon spoke directly to the cameras, resulting in more eye-to-eye contact with the audience, he was overshadowed by Kennedy's attention-getting youth, energy, and attractiveness (Highlander \& Watkins, 1962).

The "Great Debates" of 1960 left communication researchers with an array of personality and physical behaviors "on-screen" that have been used to explain why viewers reacted to the candidates as they did. These factors range from hair color, to facial bone structure, to eye-contact, to speech patterns, and inflections (Davis, 1978). The "Great Debates" also introduced communication researchers to a powerful new dimension of television. From their inception, televised presidential debates' visual impact had been in question, with the contention that television viewers found John Kennedy to be the "winner" of the "Great Debates" while radio listeners judged Richard Nixon to be the superior debater or found the two candidates equal in their performance. The first televised encounter between Kennedy and Nixon showcased powerful visual images of the handsome Kennedy confronting a sweaty, scrawny Nixon, a dubious character who sported a suspicious five o'clock shadow (Herbeck \& Mehltretter, 2005). White (1961) describes the disagreement between the listeners and viewers of the "Great Debates" as follows:

Those who heard the debates on radio believed that the two candidates came off almost equal. Yet every survey of those who watched the debate on television indicated that the Vice President had come off poorly and, in the opinion of many, very poorly. It was the picture image that had done it--and in 1960 television had won the nation away from sounds to images, and that was that (p. 318).

Whatever the facts of the Kennedy-Nixon viewer/listener difference, there is no disagreement among communication researchers that political debates' visual presentation is an area worthy of investigation (McKinney \& Carlin, 2004). Although general campaign debates in 
presidential elections were not held again until 1976, they have since become an accepted part of the American presidential campaign process (Benoit, Brazeal \& Airne, 2007).

\section{The Importance of the "Image"}

The "Great Debates" became infamous for suggesting that how a political candidate looks and speaks has a significant impact on his or her chances of being elected to public office. In $21^{\text {st }}$ century television politics, even greater attention is being paid to the images candidates project and the possible impact they may have on electoral outcomes because how a politician looks and speaks has a significant effect on his or her chances of being elected. A political candidate's presentation and style shapes his or her overall image and that image affects the audiences' votes (Rosenberg, Bohan, McCafferty, \& Harris, 1986).

Researchers have long examined the importance of candidates' physical attractiveness in political communication because aspects of physical appearance have been shown to affect people's impressions of communicators (Cesario \& Higgins, 2008). This dominance of image over substance has raised questions regarding the adequacy of the grounds upon which voters make their choices. The concern has been that image manipulation re-directs voters' attentions away from issues to candidates and at the same time prevents the voters from seeing the candidates as they truly are (Rosenberg, Kahn, Tran, \& Le, 1991).

Several political communication studies have found that physical attractiveness has been predictive of favorable source evaluations in different contexts (Allen \& Post, 2004). According to a study done by Rosenberg and colleagues (1986), a person's physical appearance can produce a clear image of that individual's character and a single photograph is enough to create a distinct and reliable image of that person. As part of their study, the researchers had participants evaluate photographs of political candidates to gauge how influential congressional candidates' physical 
appearances would be on people's voting intentions. The study found that even when clear and substantial information on candidates' party affiliations and positions on major campaign issues were presented, the photographs of the candidates exercised a strong and consistent influence on the vote. Rosenberg and colleagues (1986) concluded that a single photograph is powerful enough to provide voters with a clear image of a political candidate's character and fitness for public office and this, in turn, can influence the electoral choices they make.

Research on nonverbal communication suggests that nonverbal behavior accompanying verbal communication is at least, if not more, influential than the verbal content of the message in determining how an individual is perceived (Rosenberg et al., 1986). If the impact of a candidate's image is strong enough that a single photograph can influence voters' judgments regarding his or her competence, likability, and integrity, one has to seriously question whether there are benefits to being attractive in the political arena. Is there a political "beauty premium," such that betterlooking candidates have a higher chance of being elected to public office (Berggren, Jordahl \& Poutvaara, 2006)?

While previous research has provided general support for the hypothesis that presidential and congressional candidates' nonverbal behavior will affect how they are perceived, not much investigation has been done to test this theory with gubernatorial politicians. Previous studies have also focused mainly on examining the verbal versus nonverbal phenomenon with photographic images, leaving opportunity to test the existence of a similar trend with video footage.

\section{Non-Presidential Debates}

Although there is scant research on non-presidential debates, particularly gubernatorial debates, there have been some studies that have contributed to the body of knowledge on this subject. An experiment done in 1975 examined a primary Senate debate between Ohio incumbent 
Howard Metzenbaum and challenger John Glenn. The researchers examined the way in which media, specifically television versus radio, interacted with candidate image. Although the differences found were minimal, the better-known Metzenbaum was found to be competent regardless of exposure, while Glenn's trustworthiness was enhanced on television (Louden, 2005). Another study conducted in 1982 compared viewer reactions to a series of state-level televised debates in New Mexico with the 1980 Reagan-Anderson and Carter-Reagan presidential debates. The study found that citizens who watched one or more of the debates reported learning more from their local candidates than they did from presidential candidates (Lichtenstein, 1982). A 1991 study examined reactions to an Oklahoma gubernatorial debate and found that gubernatorial debate exposure influenced perceptions of the candidates' images and issue positions and, particularly for undecided viewers, assisted in the decision-making process (Benoit et al., 2007). Similarly, a case study conducted in 2000 found that former pro-wrestler Jesse Ventura's successful bid for Governor of Minnesota in 1998 may have been a result of his performance in the series of wellpublicized gubernatorial debates that were broadcast statewide (Louden, 2005). Ventura, a political amateur compared to his opponents Norm Coleman and Hubert Humphrey III, displayed a high level charisma toward political topics during each of the three gubernatorial debates (Lacy \& Monson, 2000).

Televised debates in campaigns for non-presidential offices are becoming increasingly common as candidates for the U.S. Congress, state governors, and city mayors use this medium to communicate with voters. In 2006, Meet the Press hosted six debates between candidates for the U.S. Senate, another indication of the importance of this medium. Furthermore, broadcasts of debates within the state and the practice of digitizing non-presidential debates so they can be viewed on the Internet combine to broaden their reach to the public (Benoit et al., 2007). 


\section{A Need for Additional Research}

Although a number of studies since the "Great Debates" of 1960 have reported that the primary impact of televised debates is the reinforcement of viewers' political predispositions, the bulk of empirical studies have found that debates manipulate viewers' attitudes toward political candidates. Televised debates can influence voters' candidate evaluations, including perceptions of candidates as caring and charismatic individuals (An \& Pfau, 2004).

Campaign communication generally tends to exert the greatest influence on voting decisions when one of the candidates is not well-known, many voters are undecided, the race appears to be a close one, and party allegiances are weak (McKinney \& Carlin, 2004). In the United States, these contingent circumstances are more common in campaigns for statewide office than in those for president, emphasizing the need for more scholarly study into non-presidential debates. Because televised debates are well-publicized, they draw relatively large audiences even in campaigns for local and statewide office. According to a 2002 survey by Fox News, $70 \%$ of American adults believed that televised debates during campaigns for offices such as state governor are important, underscoring the fact that debates remain an instrumental communication form at all campaign levels (An \& Pfau, 2004).

To date, the bulk of political communication research focuses on presidential debates. However, non-presidential debates have a greater potential to inform and influence those who view them, simply because voters know less about non-presidential than presidential candidates. Although some scholars have investigated non-presidential campaigns, gubernatorial debates especially deserve more attention because governors are the most powerful elected officials next to the President and Vice-President. The election of the state governor is a politically consequential one, and the discrete gubernatorial campaigns in up to 50 different states supply a propitious 
analytical base (Patterson \& Caldeira, 1983). State governors often campaign for the office of President and their televised gubernatorial debates are an important first presentation to the media and the public.

Televised debates in campaigns for gubernatorial offices are becoming increasingly common as candidates use this medium to communicate with voters. Since fewer people watch non-presidential debates, far fewer votes are at stake in any given gubernatorial election than in a presidential election, making the debate more critical (Benoit et al., 2007).

\section{THEORETICAL FRAMEWORK}

Public opinion of political candidates is largely influenced by the broadcast news media's presentation of political information and the influence of candidates' dispositions and behaviors (Salovey \& Glaser, 1998). According to Sullivan and Masters (1988), "in both the United States and Western Europe, television has apparently contributed to the development of a system more centered on political leaders who mobilize support in part by their 'style' of behavior" (pp. 362$363)$.

There are various theories that have been applied to political debate research through the years, the main ones being normative democratic theory, media effects theory, argumentation and debate theory, and uses and gratifications theory. Several researchers have also applied a number of interpersonal communication theories to help explain debate effects and dialogue. However, televised campaign debates are, above all, attempts by candidates to appeal to citizens for the ultimate prize, their votes. Hence, many scholars have proposed that televised debate effects could be better investigated by examining the process of attitude change through theories like social judgment and source credibility studies (McKinney \& Carlin, 2004). 


\section{The Social Judgment Theory}

Most of the theory and research on political judgment is aimed at understanding how citizens develop attitudes toward particular candidates and leaders as the basis for their choices in elections and their decisions to support or distance themselves from given leaders (Cappella \& Jamieson, 1997). Political communication researchers interested in predicting attitude change have long been drawn to the tenants of the Social Judgment Theory, which emphasizes that receivers do not evaluate a message purely on the merits of the argument (Perloff, 1993). According to the Social Judgment Theory, people assimilate communicators' attitudes that fall within their latitudes of acceptance toward their own attitudes, and contrast communicators' attitudes within latitudes of rejection away from their own. Important attitudes are thought to be especially powerful perceptual anchors that cause individuals to see others as falling primarily into one of two groups: those with whom they agree (latitudes of acceptance), and those with whom they disagree (latitudes of rejection) (Krosnick, 1988). The Social Judgment Theory also stresses the importance of the degree of involvement an individual has in the subject matter because the degree to which a person in involved in the process of judgment is a crucial factor in the kind of judgments he or she will make (Nebergall, 1966).

Social judgments refer to inferences on various social phenomena including the likelihood of social events, possession of various personality attributes, degrees of intensity of social interactions, and extent of social influences. Communication researchers have found that completing cognitive tasks involves seeking, processing, and evaluating information. Assessing how much a media message might affect a target individual or group is to render a specific type of social judgment. However, people often form such judgments with insufficient information on the factors relevant to their judgment tasks, in other words, under conditions of uncertainty. Such 
uncertainty is an unsettling psychological state that motivates individuals to engage in predictable information seeking and/or other communicative behavior. In order for individuals to make strong social judgments, the relevance, salience, and potency of the information must be as strong as their readily available conventional wisdoms of self because an individual's self-concept is known to have primacy in his or her cognitive processes. Individuals must also be sufficiently motivated to correct their instinctive egocentric tendencies in order to arrive at accurate judgments (Paek, Pan, Sun, Abisaid, \& Houden, 2005).

The Social Judgment Theory's application to televised debates dates as far back as at the 1960 presidential campaign when Hovland and Sherif looked (1961) at the role of attitudes in predicting the effectiveness of Kennedy and Nixon as they debated on television. The researchers found that the combined effect of the "Great Debates" was to convince partisans on the Democratic and Republican sides that their candidate had the edge, in proportion to the extremeness of their own political stance (Sherif, Sherif, \& Nebergall, 1965).

The persuasion and person perception aspects of Social Judgment Theory make it the ideal framework with which to interpret and integrate research on politics because voters and politicians represent social perceivers and targets. Although early political psychology research on public opinion and voter decision-making emphasized issue and ideology-based selection, much of the recent research supports the idea that candidate image (including physical appearance and expressiveness), party identification, and situational factors influence voter choice. Physical aspects of the candidate, including seemingly peripheral factors like attractiveness and facial expressions, have a substantial effect on voters' attitudes. People have been shown to rate candidates as more or less trustworthy and competent based simply on impressions formed from viewing photographs and television. Furthermore, facial expressions isolated from the 
accompanying voice of candidates during debates strongly influenced voters' impressions of candidates (Glaser \& Salovey, 1998).

\section{The Heuristic-Systematic Model of Social Information Processing}

The Heuristic-Systematic Model theorizes that message receivers can employ two different cognitive processes in a persuasive situation. When receivers have personal relevance (i.e., involvement) with the issues and sufficient cognitive capacity and motivation, they will engage in systematic processing of arguments (Paek et al., 2005). Systematic processing is characterized by careful, open-minded, and impartial scrutiny of information and is typically used when time is available to process the message. When receivers lack the necessary motivation or capacity to process information, they engage in heuristic processing of cues to lessen their judgmental uncertainty (Neuwirth, Frederich \& Mayo, 2002). Heuristic processing requires little effort or attention from the receiver who instead focuses on variables that are not directly central to the attitude object like voting for a political candidate based on his or her level of physical attractiveness, credibility, and likeability (Booth-Butterfield \& Gutowski, 1993).

When communication researchers tested the Heuristic-Systematic Model, they found that high levels of issue involvement tended to foster systematic processing and low levels of issue involvement tended to foster heuristic processing. The opinions of high-involvement subjects were more strongly influenced by the amount of argumentation contained in a persuasive message, whereas the opinions of low-involvement subjects were more strongly affected by the communicator's likability. Opinion change was found to be mediated mainly by message-based cognitions for high-involvement subjects and communicator-based cognitions for low-involvement subjects (Eagly \& Chaiken, 1983). 
The Heuristic-Systematic Model stipulates that a person's desire for accurate and sufficient information is a strong motivation for processing. Eagly and Chaiken (1993) defined heuristic processing as "a limited mode of information processing that requires less cognitive effort and fewer cognitive resources" (p. 327). By default, most people employ the principle of least effort by processing messages heuristically, judging their validity and making decisions to comply through the use of superficial cues such as the length of the message, the use of a trusted spokesperson, or the use of statistical data. While systematic processing involves the careful and extensive evaluation of information, heuristic processing entails the use of simple decision rules to form a judgment. Consequently, attitudes toward politicians based on systematic processing tend to be more permanent while attitudes based on heuristic processing are more unstable (Griffin, Neuwirth, Giese, \& Dunwoody, 2002). In a political context, voters with a high interest in politics can be assumed to use the systematic process to make their decisions while voters who are less involved in politics will rely on heuristic cues. Heuristic cues can bias the systematic process, which often leads to biased judgments about candidates running for public office (Waheed \& Chung, 2008).

According to Social Judgment Theory, viewers of a televised debate will vote for the candidate based on the strength of his or her argument. The heuristic versus systematic analysis implies that recipients of videotaped and audiotaped messages should predicate their opinions primarily on their reactions to the communicator and less on their reactions to the message content (Eagly \& Chaiken, 1983). Employing cognitive heuristics or intuition in rendering judgments is a frequently used strategy to reduce uncertainty when available information is imperfect or motivation for more information is lacking. However, this type of cognitive shortcut has its costs because a judgment formed in this manner will exhibit identifiable fallacies. When assessing 
message effects on various targets, individuals often have to compensate for the lack of information by taking whatever cues available in the context of their judgment task that could help them to arrive at a sufficiently satisfying decision such as which political candidate to vote for during an election (Paek et al., 2005).

\section{The Role of Source Credibility}

Although the "Great Debates" did not mark the beginning of formal study of the manner in which qualities of persuasive political candidates influence voters, it did serve as a catalyst to elucidate the nature of the relationship between physical appearance and persuasion (Brownlow, 1991). These qualities fall under the umbrella term of "source credibility," a term commonly used to imply a communicator's positive characteristics that affect the receiver's acceptance of a message (Ohanian, 1990). Source credibility is often defined in terms of two components expertise and trustworthiness. Expertise refers to the extent to which a debater is perceived to be capable of making the right assertions, while trustworthiness refers to the degree in which an audience perceives the assertions made by a communicator to be ones that they consider valid (Sternthal, Phillips, \& Dholakia, 1978). Source trustworthiness and expertise influence attitude modification to the extent that those judged to be trustworthy or expert are likely to produce both immediate attitude change and behavioral compliance. Sources will be judged as trustworthy if they argue against their own self-interest or if they are judged to be honestly communicating facts that they consider valid. The persuasive effects of credibility remain even when an audience is not completely attentive to the message, although the effects are not as strong when the content of the message being communicated is of personal relevance to the perceiver (Brownlow, 1991). According to Teven (2008), "source credibility operationalizations of images may succeed when 
voters are using those traits as arguments and fail when they are using them as cues while elaborating on candidates' issue arguments" (p. 394).

The role of source credibility has been the subject of various political communication studies over the years because politicians are skilled communicators who influence public opinion. A candidate's perceived credibility is an important component of communication since messages from sources perceived to be highly credible are more persuasive; conversely, messages from political candidates thought to be disreputable could have a boomerang effect (Teven, 2008). According to Andreoli and Worchel (1978), television is a more involving medium than radio, so it highlights certain communicator characteristics like trustworthiness, expertise, and likeability.

Source credibility is an important factor for communication researchers to consider when investigating political campaigns. A recent study looked at the front-line Democratic and Republican contenders for their respective political party's nomination during the 2008 presidential election. The researchers discovered that political candidates' believability and likeability had significant, positive relationships with voters' perceptions of candidate credibility, demonstrating that source credibility is a major determinant in voter behavior and candidate selection (Teven, 2008).

\section{Research Questions and Hypotheses}

The overall research question guiding this study is: During a televised gubernatorial debate, which cues - verbal or nonverbal will be more persuasive to viewers? Two hypotheses regarding verbal versus visual cues were derived from the extant literature. The two overall theories used in this study, Social Judgment Theory and the Heuristic-Systematic Model, as well as findings from source credibility studies, provided evidence regarding how viewers would process information about gubernatorial candidates during televised debates. 
According to the Social Judgment Theory, individuals will consider credible information relevant to their own stance on issues (Paek et al., 2005). They will assimilate communicators' attitudes that fall within their latitudes of acceptance toward their own attitudes, and contrast communicators' attitudes within latitudes of rejection away from their own (Sherif, Sherif, \& Nebergall, 1965). Therefore:

H1a: If the subject matter discussed by the gubernatorial candidate is within the latitudes of acceptance of the viewer, then he or she will have a positive attitude toward that candidate based on the strength of his verbal arguments.

H1b: If the subject matter discussed by the gubernatorial candidate is within the latitudes of acceptance of the viewer, then he or she will be more likely to vote for that candidate based on the strength of his verbal arguments.

When message content matters little to audiences, the Heuristic-Systematic Model comes into play. In the systematic view of persuasion, message recipients focus primarily on persuasive arguments in forming their opinion judgments, whereas in the heuristic view, recipients engage in little, if any, detailed processing of message content and, instead, tend to use simple decision rules based on cues like the communicator's identity in judging message acceptability (Eagly \& Chaiken, 1983). If the viewer of a televised gubernatorial debate has no opinion on the subject matter being discussed, then he or she will form an opinion on that candidate based on the strength of his visual cues. Therefore:

H2a: The more physically appealing a candidate appears during a televised debate, the more likely the viewer is to have a positive attitude toward him or her.

H2b: The more physically appealing a candidate appears during a televised debate, the more likely the viewer is to vote for him or her. 


\section{METHOD}

This research seeks to identify specific source, message, or receiver factors that enhance or inhibit persuasive effectiveness of a political message. The focus on the identification of specific causal variables in persuasion makes experimental research useful to mass communication researchers. In the past, classic studies of both source and message effects on persuasion and attitude change have relied on experimental methods (Miller \& Levine, 1996).

In surveying the limited analysis of debates' visual content, political communication researchers have found that the bulk of available research concentrates on televised debates that occurred from 1960 to 1988. Most of the research methods used in these studies were surveys, rhetorical analyses, and content analyses. However, in order to adequately gauge the effects of debates' visual influence, experimentation and viewer effects research are also needed (McKinney \& Carlin, 2004).

To date, almost all of the research conducted on this topic has focused solely on televised presidential debates. Lichtenstein (1982) describes the lack of experimentation in this particular realm of political communication as follows:

The lack of research on televised debates, other than those concerned with Presidential elections, increases the probability that findings may be improperly generalized. Such generalizations do not take into account important differences in televised debates between candidates for local offices and the "Great Debates" for the office of President. For example, few local campaigns can attract the publicity and public interest of the race for the Presidency. Because of this, local candidates may be less known to the public and their positions on various issues less clear. (p. 292).

\section{Design}

The empirical method used in this study was the repeated measures within-subjects design. In this experimental design, instead of assigning different people to different manipulations, each 
participant is exposed to multiple manipulations. The effects of the various manipulations appear as variations within the same person's performance rather than as differences between groups of people (Wimmer \& Dominick, 2006).

This research study incorporated a 2 x 2 experimental design: 2 (visual: low/high) x 2 (verbal: low/high) with four versions of the message presented in random order. Within-subject factors generally give researchers a clearer picture of treatment effects because the variance within treatment levels is dramatically reduced by having each subject view each manipulation. Because treatment effects are determined by each subject's averaged response within a treatment, divided by the same subject's response averaged over all the treatments, each participant serves as his or her own control group. Within-subject designs may reduce error variance as much as one half to one fifth that of comparable between-subject factors (Reeves \& Geiger, 1994).

The practical rationale for within-subject designs is quite compelling because the same power in experiments can be achieved with fewer subjects and the set-up time for each subject is substantially reduced. In a within-subject design, each person accounts for multiple observations, reducing the burden of measuring a number of individuals a single time (Reeves \& Geiger, 1994).

A number of threats to both internal and external validity were dealt with in the design of this experiment. Because the same individual is measured repeatedly, this type of design was vulnerable to validity issues relating to: subject learning, fatigue, measurement order, and treatment effects (Stevens, 2002). In this study, these issues were countered by: varying the presentation of questions; allowing participants to become comfortable with the experimental task; and giving participants a series of questions between each stimulus presentation to serve as a "buffer" between each viewing. Furthermore, to limit participant fatigue and subject mortality, the total length of the 
experiment, including obtaining consent and debriefing participants, was kept to approximately 45 minutes (Calfee, 1985).

\section{Participants}

Young adults (aged 18 to 24) were selected as the sample for both the pre-test and experimental procedures. This demographic was chosen because voters between the ages of 18 and 24 represent the portion of the electorate with the largest disparity between the rates that register to vote and actually vote. This voting block remains proportionately low in terms of those who are classified as "regular voters," with only 22 percent of 18- to 24-year-olds reporting that they vote regularly (Glynn, Huge, \& Lunney, 2009).

Political scholars and observers have repeatedly expressed concerns about a lack of public affairs knowledge and anemic levels of civic engagement among young voters. Since 1971, when 18-year-olds were given the right to vote in all local, state, and federal elections, electoral turnout among 18- to 24-year-olds has been lower than that of any other age group (Pinkleton \& Austin, 2004). Only 11.6 million voters between the ages of 18 and 24 made their way to the polls during the 2004 election cycle and even fewer voters ( 8.6 million) voted during the 2000 election cycle (Johnson, 2007). Media and political communication researchers have attributed this political apathy to the fact that young adults distance themselves from outlets that disseminate political information. Large portions of Americans under the age of 30 do not watch or listen to the news on television or radio and don't read about public affairs in newspapers or magazines (Bennett, 1997).

This evidence made the 18 to 24 demographic exceptionally attractive in terms of studying the verbal versus visual components of televised debates. Politicians running for office on the state and local levels do not receive as much media attention as those running for office on the national 
level. Hence, youth voters are not likely to possess a great deal of knowledge on gubernatorial candidates' stances on issues. When this age group watches a series of debates between gubernatorial candidates, they are not likely to have predetermined attitudes about the candidates, improving the validity of this study.

\section{Stimuli Selection}

In this study the manipulated independent variables were 60-second clips of televised gubernatorial debates containing verbal and visual messages. The debate clips were developed from footage obtained from a video-sharing website, and from various television networks and public broadcasting stations. Real debate footage was used (as opposed to those created in a media lab) so that findings could be generalized to such gubernatorial forums.

The study refrained from showing participants debates from the states of Ohio, Kentucky, Pennsylvania, New Jersey, New York, Virginia, Delaware, and Maryland because of these states' proximity to the state where the study was conducted. This diminished voter bias that could have otherwise affected the validity of the study. Gubernatorial debates from the states of California, Florida, Alaska, Illinois, South Carolina, and Texas were also not shown to participants because gubernatorial candidates from those states appeared in the national media spotlight when campaigning and continue to be widely-recognized. In order to minimize the amount of voter bias in the study, the issues discussed in the debates did not include "hot button" topics such as abortion, gay marriage, socialized medicine, and gun control because those subjects tend to have extreme Republican or Democratic leanings. Instead, the selected stimuli revolved around issues like energy reform, higher education, and taxes.

The clips shown to participants were strategically chosen from all major sections of the country: the Western United States (Utah, Washington, Montana and Idaho), the Midwest (North 
Dakota and Missouri), the South (Georgia and North Carolina) and the East (Rhode Island and New Hampshire). Participants were only shown clips of debates between the leading Democratic and Republican candidates. Candidates from third parties like the Constitution Party, the Green Party, and the Libertarian Party were not included in this study.

Televised debate clips were used in this study for a number of reasons. It has been argued that individual allocations of resources are not the same for each media type since different media require different levels of effort during information processing (e.g., newspaper requires more than television) (Chaffee \& Schleuder, 1986; Krugman, 1971). This line of research posited that passive media like television require less attention on the part of the viewer to process incoming stimuli. Active media on the other hand, require individuals to engage in cognitive processing as the individuals have to make sense of the stimuli on their own. Contradictory to this view, Anderson and Burns (1991) posited that television is a medium that elicits and maintains attention. Nonetheless, using a mixture of media would have likely introduced a confounding variable.

The previous sections highlighted the fact that different message features like a speaker's physical attractiveness and the quality of his verbal arguments can influence individuals' information processing. It is also interesting to note that media that support presentation of those features can influence processing levels. For example, radio consists solely of auditory stimuli meaning it cannot rely on visuals to evoke emotion and arousal. On the other hand, television can use both auditory and visual information to evoke those feelings. Findings by Lang and colleagues (A. Lang, 1995; A. Lang, Strickwerda, \& Summer, 1993) provide evidence that suggests that information-rich media such as television (with both audio and video presentation of information), may increase arousal and attention while at the same time decreasing encoding, storage, and retrieval. Another strength of this medium is that television viewing is not a novel experience that 
will interfere with experimental procedures as it ranks third only to sleeping and work in occupying an individual's day (Oskamp \& Schultz, 1998).

\section{Measures}

The independent variables that were manipulated in this study were the verbal and visual cues displayed by politicians during a televised gubernatorial debate.

$\underline{\text { Verbal Measures (See Appendix A for full measure) }}$

The following verbal measures were adapted from the Nonverbal Immediacy ScaleObserver Report developed by McCroskey and Johnson (2003) and pre-tested in this study:

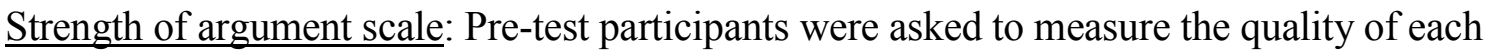
candidate's verbal arguments on a Likert scale of 1 to 5 with $1=$ Strongly Disagree and $5=$ Strongly Agree. Pre-test participants were asked to indicate how conversationally each candidate spoke and how well they could understand his or her arguments. The scale was reported by McCroskey and Johnson to have an estimated alpha reliability of 0.90 . In this study, the reliability analysis reported an average Cronbach's alpha of 0.610 . The highest alpha value was 0.801 and the lowest alpha value was 0.295 .

$\underline{\text { Visual Measures (See Appendix B for full measure) }}$

The following scale for measuring physical attractiveness was used in this study: Physical attraction: This five-point Likert scale was developed by McCroskey and McCain (1974) and has been widely used by researchers in communication and psychology because attraction has been positively associated with a host of communication behaviors and perceptions, providing ample evidence of construct validity. Communication researchers have also found evidence that physical attraction influences voter preferences (Rubin, Palmgreen \& Sypher, 2004). The scale asked participants during the pre-test portion to 
indicate if they liked each debater's physical appearance and evaluate how handsome or pretty each debater was. The scale was reported by McCroskey and McCain to have an estimated alpha reliability of 0.860 . In this study, the reliability analysis reported an average Cronbach's alpha of 0.817 . The highest alpha value was 0.899 and the lowest alpha value was 0.222 .

The dependent variables that were measured during the experimental procedures were participants' overall attitudes (positive or negative) toward the debaters and their intent to vote for those candidates. Attitudes are evaluative tendencies and can typically be phrased in terms of like or dislike and favor or disfavor (Eagly \& Chaiken, 1993). Behaviors are largely a function of individuals' perceptions in the immediate situation in which the attitude object is encountered (Fazio, 1986).

Attitudes toward speaker (See Appendix C for full measure)

The viewers' overall attitudes (positive or negative; like or dislike) toward the debaters were measured in the experimental part of the study. A nine-point Semantic differential scale intended to measure a person's attitude toward another person was used. The scale, developed by Till and Shimp (1998), asked the participants to indicate their attitudes about each debater on screen - good or bad, favorable or unfavorable and positive or negative. The alpha reliability of this scale was reported by Till and Shimp to be 0.98 . The reliability analysis reported an average Cronbach's alpha reliability of 0.892 . The highest alpha value was 0.927 and the lowest alpha value was 0.833 .

Voting intent (See Appendix D for full measure) A seven-point Semantic differential scale was used to measure each participant's stated inclination to vote for a particular candidate. The scale asked participants to indicate how 
certain or uncertain and how likely or unlikely they were to vote for each candidate. The most recent version of the scale was adapted and used by Jones, Mothersbaugh, and Beatty (2000) who reported an alpha reliability of 0.99 . In this study, the reliability analysis reported an average Cronbach's alpha of 0.915. The highest alpha value was 0.944 and the lowest alpha value was 0.882 .

\section{External Validity and Generalizability}

Since a convenience sample of college students was used in this experimental study, it was important to address potential validity and generalizability issues that could arise as a result of using this sample. External validity is defined as the ability to generalize to, or across, a particular target persons, settings, and times. More recently, researchers have suggested expanding the definition to include generalizability across messages (Shapiro, 2002). To increase external validity, multiple treatment interference was controlled by randomizing the presentation order of messages.

Communication researchers and social scientists have long debated whether or not the use of student samples jeopardizes the validity of research. However, several researchers have found that experimental studies do not have to use representative samples for two reasons. First, experiments exercise a strict time ordering of the factors and random assignment to conditions; therefore, they are less susceptible to the problem of third variables. Second, any research that tests the relationship between factors allows for the falsification of theories if the expected relationships do not hold. As a result (regardless of whether the data was gathered from a representative sample of the population or from subsamples), if the relationship only holds for a portion of the sample, or is contingent upon some other condition occurring, then examining the 
relationship provides a test of the theory across these circumstances (Basil, Brown, \& Bocarnea, 2002).

According to a meta-analysis conducted of research comparing student and non-student subjects, the parameters derived from student research sometimes differed in magnitude and direction from research with adults, but were not superior or inferior to an adult sample. While this does not indicate that college students are always sufficient sample sizes, it does suggest that nonrepresentative samples can often prove to be sufficient tests of theories (Basil et al., 2002).

\section{Manipulation Check}

In studies of the effects of message variations on persuasive outcome variables like attitude change, researchers have arrived at three classes of research claims. The Class II claim, which concerns the effect of a message variation on persuasive outcomes, is the one that pertains to this experimental study (O’Keefe, 2003).

O'Keefe (2003) cites an experimental study that examined the degree to which metaphorical and non-metaphorical advertisements produced differences in brand name recall. The researchers wanted to find out whether messages containing such a metaphor would be more persuasive than messages without one. According to O'Keefe (2003), when addressing such research questions, manipulation checks are unnecessary because the researchers could simply compare the effect of different message conditions on outcome variables. While researchers have to be careful in creating the experimental messages, the adequacy of the message property is not appropriately assessed by inquiring about participant perceptions of the message.

In this study, no manipulation check was performed on message type as the stimuli were defined in terms of message properties and pre-tested for those properties. Thus, by defining the stimuli in terms of intrinsic features, no need for a manipulation check exists as the stimuli either 
are, or are not, debaters with either low or high levels of verbal and visual effectiveness (O'Keefe, 2003). This was assessed prior to the experiment using the stimuli pre-test outlined below.

\section{Pre-Test Procedures and Findings}

The stimuli used in the final experiment were pre-tested to determine which debate clips contained similar levels of verbal and visual content. A series of 40 possible 60 -second debate clips were shown to 73 participants enrolled in an entry level journalism course at a large Eastern university. The exact wording for the pre-test questions can be found in Appendix E. Following informed consent, participants were shown the clips one at a time and rated each clip according to the following scales: Verbal Argument Scale and Physical Attraction Scale. The entire process took approximately one hour to complete. At the end of the study, participants were asked a series of socio-demographic questions, were thanked for their participation, and were debriefed.

Of the 73 students that participated, 15 surveys were thrown out due to incomplete answers leaving a total sample of 58 participants. IRB approval was obtained for the pre-test and experimental portions of the study (see Appendix F) and the students signed IRB consent forms before the pre-test procedures began. In return for completing the experiment, students earned ten extra credits points, an amount deemed appropriate by their instructor. The School of Journalism has an IRB-approved extra credit policy (see Appendix G) in place.

Following each clip viewing, participants were asked to rate each candidate on a 15-item semantic differential scale of 1-7 to determine how visually and verbally effective each gubernatorial candidate was. To calculate the overall value of each message, responses were summed for each of the 15 items across the debate clips and averaged. Items with an * were reverse-coded so than an average of " 7 " indicated a positive response and an average score of "1" 
indicated a negative response. The Verbal Argument Scale reported an average alpha reliability of 0.610 and the Physical Attraction Scale reported an average alpha reliability of 0.817 .

The pre-test portion of the study was conducted on 58 WVU School of Journalism participants who hailed from varying majors, ethnicities, ages, and political affiliations. The participating students' ages ranged from 18 to 32 and they represented all four years of coursework from freshmen to seniors. The participants' fields of study ranged from journalism, fashion merchandising and marketing to criminology, sports management, and multidisciplinary studies. The participants were asked to indicate their political affiliations as well as those of their parents. In order to ensure that the content in the video clips would be universally understood, participants were also asked to indicate whether or not English was their primary language.

After computing the average verbal and visual value of each debate clip, those clips which fell in the top $1 / 3$ were determined to be high visual and/or verbal messages and those in the bottom $1 / 3$ were determined to be low visual and/or verbal messages. Those messages with visual and verbal means in the middle regions were not used in the final experiment.

Following analysis of the pre-test data, 16 messages were selected to be the stimuli in the final experiment with an equal number of messages in each cell of the $2 \times 2$ design. The verbal and visual scales used eight questions to create an overall rating of 56 possible points. This number was then divided by 8 to get the mean. The four debate clips that received the highest mean ratings (Average Verbal Mean $=25.20 \&$ Average Visual Mean $=11.75)$ on the verbal and visual scales were selected to be the High Verbal/ High Visual stimuli. The four debate clips that received the highest mean ratings on the verbal scale but the lowest on the visual scale were selected to be the High Verbal/Low Visual stimuli (Average Verbal Mean $=24.50$ \& Average Visual Mean $=8.60$ ). The four debate clips that received the lowest mean ratings on the verbal 
scale but the highest on the visual scale were selected to be the Low Verbal/High Visual stimuli (Average Verbal Mean $=21.33 \&$ Average Visual Mean $=10.70)$. The four debate clips that received the lowest mean ratings on the verbal and visual scales were selected to be the Low Verbal/Low Visual stimuli (Average Verbal Mean $=21.57 \&$ Average Visual Mean $=8.77$ ).

\section{Experiment Implementation}

Data for the final experiment was collected using MediaLab V 2008 on full-screen computers with color screens. The participants were able to listen to the candidates' arguments through headphones with volume adjusters so they could tailor the sound level to their liking. The MediaLab 2008 software allowed for a factorial design to be used in this experiment with different stimuli presentation orders and integrated questionnaires (i.e., demographic information as well as questions about attitude and voting intent between video clips).

The experiment was conducted over the course of one week on the campus of a large Eastern university. A total of one hundred and seventy-nine participants $(\mathrm{N}=179)$ from several advertising, multi-media reporting, media writing, and public relations courses in the School of Journalism participated in the experiment. According to apriori power estimates, a sample size of 96 participants was necessary at a power of 0.80 to detect a medium effect size $(0.25)$ at the 0.05 significance level for a repeated measures within-subjects design.

As part of the final experiment procedures, participants were assigned to individual experimental sessions based on their availability. When they arrived, participants were greeted by the researcher, who explained the purpose of the study, addressed questions and concerns, and obtained informed consent. During this introduction, participants were assured that they could decline or withdraw from the study at any time. They were also informed that their responses 
would be kept strictly confidential. The participants signed IRB consent forms (see Appendix H) prior to doing the study and were given extra credit by their instructors for their participation.

Following the informed consent process, participants were seated at four desktop computers, and the computer chairs, monitors, and headphones were positioned to the participants' comfort. The volume levels were individually set loud enough for participants to adequately hear the audio track on each computer. Participants were then instructed that they would view a series of debate clips and be asked to rate their responses to each clip following.

Afterward, participants were instructed as to how the experimental portion would proceed, and were given the opportunity to warm-up by viewing a 30 -second commercial to become familiar with the experimental task as well as the desktop commands. Once participants were comfortable with the study, the experiment began. The students viewed a series of 16 gubernatorial debate clips that were chosen based on the above mentioned pre-test findings. Transcripts for each of the sixteen clips can be found in Appendix I. The order of each viewing was randomized in order to control for any carryover effects of prior messages ${ }^{1}$. After viewing each video clip, participants completed questions regarding attitude and intention to vote. The participants were administered a survey at the end of the experiment to gauge their attitudes toward the topics discussed in the videos. They were asked to indicate their political affiliations as well as those of their parents. Each participant was also asked to indicate his or her age, grade point average, year in school, and whether or not English was his or her primary language (See Appendix $\mathrm{J}$ for final experiment questionnaires).

\footnotetext{
1 This type of counterbalancing does not remove the main effects of order, rather it distributes the effects over the levels of the stimuli so that they are not confounded, thus order becomes a control variable (Stevens, 2002).
} 
After completing the experiment, participants' names were recorded for extra credit points and the students were debriefed as to the overall premise of the study and again asked if they had any questions or concerns. They were also asked if they could identify the purpose of the experiment. The entire process took approximately 45 minutes to complete. Prior to, and following each session, the researcher checked the desktops and computer programs to ensure that they were functioning properly.

\section{FINDINGS/RESULTS}

Twenty-nine surveys were thrown out due to incomplete answers, leaving a total sample of 150 participants $(\mathrm{N}=150)$. To analyze the results of the experiment, data was entered into a computer-based statistics program, Statistical Package for the Social Sciences (SPSS) 16.0 to analyze the variances. Preliminary analyses performed on the data included Cronbach's alpha reliability coefficients for the Attitude toward Debater and Intent to Vote scales. Repeated measures one way analysis of variance (ANOVA) was used with Bonferroni Post Hoc tests to correct for Type 1 error. In addition, Pearson's $r$ correlation statistical test (Salkind, 2004) was used to test the relationship and correlation of variance. The research committee chair oversaw and assisted in the statistical analysis.

A significance criterion of 0.05 was adopted for each hypothesis test to protect against Type 1 error. Prior to participation recruitment, power was set at 0.80 to ensure that the experiment was sensitive enough to detect real effects. The overall power of the experiment was also increased by efficiently using subjects in a repeated measures factorial design with withinsubject variables. Consistent with Cohen (1992), the number of subjects tested in this study was large enough to detect within-subject differences at a 0.25 medium effects size. 
Repeated measures factorial ANOVAs were used to examine the continuous dependent variables of Attitude toward Candidates and Intent to Vote. The more conservative multivariate Greenhouse-Geisser adjusted $\mathrm{F}$ test with degrees of freedom rounded down to the nearest whole number (as opposed to Wilks' Lambda) was used (Stevens, 2002). This was done to protect against Type 1 error by producing a more accurate $p$ value based on adjusting the degrees of freedom downwards (Baguley, 2004).

For each repeated measures ANOVA, simple interactions and main effects of the independent variables (HighVerbal/HighVisual, HighVerbal/LowVisual, LowVerbal/HighVisual and LowVerbal/LowVisual) on the dependent variables were examined using post hoc analyses with Bonferroni corrections to adjust for multiple family-wise comparisons. When an interaction effect was not present, the main effect of each independent variable was generalized against the levels of the other independent variables.

\section{Attitudes toward Topics}

Hypothesis 1a and hypothesis $1 \mathrm{~b}$ predicted that if the topics discussed by each candidate were important to the viewer, then he or she would have a positive attitude toward the candidate and would be more likely to vote for him based on the strength of his verbal performance. During the experimental procedures, participants were asked to rate their attitudes toward each of the four topics on a scale of 1 through 9 . The four topics discussed by the candidates centered on implementing higher education reform, dealing with the energy crisis, lowering the price of gasoline, and lowering individual states' income and small business taxes. A series of ANOVAs found no significant difference where one topic was highly significant to viewers over another (significance criterion used was $\mathrm{p}<0.05$ ). Results indicated that participants had neutral feelings toward each of the four topics (See Table 1). Therefore, hypotheses 1a and 1b were not supported. 
Since the topics had no influence on the viewers, analyses of the impact of verbal arguments were conducted on the results of the messages independent of the topics presented.

Table 1: Means and Standard Deviations of Topics Discussed by Gubernatorial

\section{Candidates}

\begin{tabular}{|l|l|l|}
\hline Topic & Mean & Std. Deviation \\
\hline T1. Education reform & 6.65 & 1.87 \\
\hline T2. Energy reform & 6.85 & 1.68 \\
\hline T3. Lowering gas prices & 6.78 & 2.00 \\
\hline T4. Income and business tax reform & 6.94 & 1.78 \\
\hline
\end{tabular}

\section{Attitudes toward Gubernatorial Candidates}

Regarding hypothesis $2 \mathrm{a}$, which predicted that viewers would demonstrate more positive attitudes toward more physically attractive debaters, results indicated that there was a significant interaction between debater type and attitude, $\mathrm{F}(1,149)=71.8, \mathrm{p}<0.001$ and power $=1.0($ See Table 2). 
Table 2: Analysis of Variance result for relationship between Verbal * Visual measure and Attitude toward Debater $(\mathrm{N}=150)$

\begin{tabular}{|c|c|c|c|c|c|c|c|}
\hline Source & $\begin{array}{l}\text { Sum } \\
\text { of } \\
\text { Squares }\end{array}$ & df & $\begin{array}{l}\text { Mean } \\
\text { Square }\end{array}$ & $\mathbf{F}$ & Sig & $\begin{array}{l}\text { Partial } \\
\text { Eta } \\
\text { Squared }\end{array}$ & Power \\
\hline Verbal & 0.11 & 1.00 & 0.11 & 0.001 & 0.98 & 0.00 & 0.050 \\
\hline Error & 14086.40 & 149.00 & 94.50 & & & & \\
\hline Visual & 2.667 & 1.00 & 2.67 & 0.030 & 0.86 & 0.00 & 0.053 \\
\hline Error & 13329.83 & 149.00 & 89.46 & & & & \\
\hline $\begin{array}{l}\text { Within- } \\
\text { Subjects } \\
\text { Verbal*Visual } \\
\text { Interaction }\end{array}$ & 6029.34 & 1.00 & 6029.34 & 71.8 & 0.00 & 0.325 & 1.00 \\
\hline $\begin{array}{l}\text { Interaction } \\
\text { Error }\end{array}$ & 12517.16 & 149.00 & 84.01 & & & & \\
\hline
\end{tabular}

Notes: Significance criterion used was $\mathrm{p}<0.05$

Post hoc tests using the Bonferroni adjustment indicated that overall, participants expressed significantly more positive attitudes to LowVerbal/HighVisual debaters $(\mathrm{M}=72.87)$ versus HighVerbal/LowVisual debaters $(M=72.71)$. In addition, participants expressed more positive attitudes toward HighVerbal/HighVisual debaters $(\mathrm{M}=66.50)$ versus LowVerbal/LowVisual debaters $(\mathrm{M}=66.40)$. Therefore, hypothesis $2 \mathrm{a}$ was supported as participants expressed significantly more positive attitudes for visually attractive gubernatorial politicians over other candidates (see Table 3). 
Table 3: Means and Standard Deviations for Attitudes toward Gubernatorial Candidate

\begin{tabular}{c|llll} 
IV & $\begin{array}{l}\text { Message Type } \\
\text { HighVerbal/ } \\
\text { HighVisual }\end{array}$ & $\begin{array}{l}\text { LowVerbal/ } \\
\text { LowVisual }\end{array}$ & $\begin{array}{l}\text { HighVerbal/ } \\
\text { LowVisual }\end{array}$ & $\begin{array}{l}\text { LowVerbal/ } \\
\text { HighVisual }\end{array}$ \\
\hline & $\begin{array}{l}\text { Low } \\
\text { M }\end{array}$ & 66.40 & 72.71 & 72.87 \\
SD & 11.8 & 11.6 & 11.9 & 11.3 \\
Notes: Higher scores indicate more positive attitudes toward each gubernatorial candidate. &
\end{tabular}

\section{Viewers' Intent to Vote}

Regarding hypothesis $2 \mathrm{~b}$, which predicted that viewers would vote for the more physically attractive debaters, results indicated that there was a significant interaction between debater type and intent to vote, $F(1,149)=67.05, \mathrm{p}<0.01$ and power $=1.0($ See Table 4$)$. 
Table 4: Analysis of Variance result for relationship between Verbal * Visual measures and Intent to Vote $(\mathrm{N}=150)$

\begin{tabular}{|c|c|c|c|c|c|c|c|}
\hline Source & $\begin{array}{l}\text { Sum } \\
\text { of } \\
\text { Squares }\end{array}$ & df & $\begin{array}{l}\text { Mean } \\
\text { Square }\end{array}$ & $F$ & Sig & $\begin{array}{l}\text { Partial } \\
\text { Eta } \\
\text { Square }\end{array}$ & Power \\
\hline Verbal & 0.042 & 1.00 & 0.042 & 0.000 & 0.99 & 0.000 & 0.050 \\
\hline Error (Verbal) & 14630.71 & 149.00 & 98.19 & & & & \\
\hline Visual & 459.38 & 1.00 & 459.38 & 5.23 & 0.024 & 0.034 & 0.62 \\
\hline Error (Visual) & 13083.38 & 149.00 & 87.81 & & & & \\
\hline $\begin{array}{l}\text { Within- } \\
\text { Subjects } \\
\text { Verbal*Visual } \\
\text { Interaction }\end{array}$ & 6201.74 & 1.00 & 6201.74 & 67.05 & 0.00 & 0.31 & 1.00 \\
\hline $\begin{array}{l}\text { Error } \\
\text { Interaction }\end{array}$ & 13781.02 & 149.00 & 92.50 & & & & \\
\hline
\end{tabular}

Notes: Significance criterion used was $\mathrm{p}<0.05$

Post hoc tests using the Bonferroni adjustment also indicated that overall, participants expressed a significantly higher intent to vote for LowVerbal/HighVisual candidates $(\mathrm{M}=66.78)$ versus HighVerbal/LowVisual ones $(\mathrm{M}=65.04)$. Findings also indicated a significantly higher intent to vote for HighVerbal/HighVisual debaters $(\mathrm{M}=60.36)$ versus LowVerbal/LowVisual debaters $(M=58.60)$. Therefore, hypothesis $2 \mathrm{~b}$ was supported as participants expressed significantly higher intentions to vote for visually attractive gubernatorial candidates than other candidates (see Table 5). 


\section{Table 5: Means and Standard Deviations for Intent to Vote for Gubernatorial Candidate}

\begin{tabular}{l|llll} 
IV & $\begin{array}{l}\text { Message Type } \\
\text { HighVerbal/ } \\
\text { HighVisual }\end{array}$ & $\begin{array}{l}\text { LowVerbal/ } \\
\text { LowVisual }\end{array}$ & $\begin{array}{l}\text { HighVerbal/ } \\
\text { LowVisual }\end{array}$ & $\begin{array}{l}\text { LowVerbal/ } \\
\text { HighVisual }\end{array}$ \\
\hline & $\begin{array}{l}\text { Low } \\
\text { M }\end{array}$ & 58.60 & 65.04 & 66.78 \\
SD & 11.8 & 13.6 & 13.4 & 13.5 \\
Notes: Higher scores indicate greater intent to vote for each gubernatorial candidate.
\end{tabular}

Overall, the results suggest that regardless of the content of the debate topics discussed, viewers had the most positive attitudes toward the LowVerbal/HighVisual gubernatorial candidates. The findings also suggest that those viewers had the greatest intentions to vote the LowVerbal/HighVisual candidates into public office. Since the topics discussed by the debaters elicited fairly neutral responses from the viewers, one can conclude that they did not have much influence on their attitudes toward or intentions to vote for any particular candidate.

\section{DISCUSSION}

The primary objective of this experiment was to examine whether televised gubernatorial debaters' verbal or nonverbal cues would be more persuasive to the viewers watching their performances. The social judgment-involvement approach theorizes that the degree to which people are involved with topics being discussed is a crucial factor in the judgments they will make. Individuals evaluate issues to see if they match their own positions and will therefore judge those issues closer to their personal views. Similarly, if the positions under consideration are relatively far from the individuals' views, they will tend to be more violently in disagreement with those particular issues (Nebergall, 1966). Hypotheses 1a and $1 \mathrm{~b}$ contended that if the topic discussed by 
the debater was important to the viewer, then he or she would have a positive attitude toward that candidate and would be more inclined to vote for him based on the strength of his verbal arguments. Hypotheses $1 \mathrm{a}$ and $1 \mathrm{~b}$ were not supported. The four topics discussed in the debate clips had no significant influence on viewers as each topic elicited neutral responses from the participants (See Table 1). However, subsequent analyses indicated that argument strength did not play a significant role in attitude or intent to vote.

One explanation for the lack of interest in the topics presented could be attributed to the sample population chosen for the study. Scholars have long discussed people's political attitudes and behaviors and have expressed concerns regarding the lack of civic engagement and the widespread apathy among young people today. Although recent survey research has found that young voters are active Internet users and use it as one of their primary sources for political information, post-election results consistently show that college students are the group with the lowest voter turnout in elections among any age groups (Zhang \& Pinkelton, 2009).

Despite the apathy demonstrated in the debate topics, results did indicate the existence of several correlations between participants' demographic information and their attitudes toward certain topics presented. One correlation was found between the participants' parents' political affiliations and the topic of education reform $(\mathrm{p}<0.05)$. Another correlation was found between participants' families' estimated annual household incomes and the topic of higher education $(\mathrm{p}<$ 0.05). These correlations can be explained by the fact that parents have significant influences on their children's political and social values. According to Tims (1986), parents transmit their social values and political attitudes and beliefs to their household. They decide the family's discussion about politics, their household's media environment, and the amount of exposure their children 
will have to certain political information and models. This political socialization influences their children's attitudes and beliefs toward certain issues and candidates.

The study's findings also showed that those participants for whom English was a second language had more positive attitudes toward the candidates who discussed lowering gasoline prices and reducing the country's dependence on foreign oil $(\mathrm{p}<0.05)$. This can be attributed to the fact that those participants hailed from Latin America and Middle-Eastern nations where local gasoline prices are kept low as a benefit to those nations' citizens (CNN Money, 2005).

Since results indicated that the topics discussed during the debate clips had no influence on the participants' choices, the results of the messages (HighVerbal/HighVisual, LowVerbal/HighVisual, HighVerbal/LowVisual and LowVerbal/LowVisual) were analyzed independently. Hypothesis 2 was based on the heuristic-systematic model's assumption that television viewers do not always take the time to make well-founded judgments and often base their decisions on peripheral cues because they are easier to process (Bilandzic, 2003). The prediction was that if viewers were apathetic toward the issues discussed by the candidates, they would rely on the strength of the debaters' visual cues like their physical attractiveness. Hypothesis 2a predicted that those viewers would be more likely to have positive attitudes toward the more attractive debaters and hypothesis $2 \mathrm{~b}$ predicted that they would be more likely to vote for those candidates during an election.

Hypotheses $2 \mathrm{a}$ and $2 \mathrm{~b}$ were supported by the results of the study. The study found that viewers had the most positive attitudes toward the LowVerbal/HighVisual $(\mathrm{M}=72.87)$ debaters and were also most likely to vote for those gubernatorial candidates during an election (See Table 3). Although viewers were found to be fairly receptive to HighVerbal/LowVisual ( $M=65.04)$ debaters, results indicated that they would still prefer to vote for the LowVerbal/HighVisual $(\mathrm{M}=$ 
66.78) candidates (See Table 5). Results also showed that viewers did not have very positive attitudes toward HighVerbal/HighVisual $(\mathrm{M}=66.50)$ and LowVerbal/LowVisual $(\mathrm{M}=66.40)$ debaters and were also not inclined to vote for those candidates. Findings also indicated that the participants' political affiliations (Democrat, Republican, Moderate, Other, etc.) did not influence their decisions to be more favorable toward certain candidates.

The support for hypotheses $2 \mathrm{a}$ and $2 \mathrm{~b}$ suggests that during a televised gubernatorial debate, a candidate's physical attractiveness and camera-friendly appearance tends to resonate more with viewers than his or her verbal arguments. In keeping with the trend of the "Great Debates" of 1960, viewers were significantly more likely to vote for the better-looking gubernatorial candidates, regardless of the issues being discussed or the quality of the verbal arguments being made. This finding can be attributed to the fact that even in the $21^{\text {st }}$ century, a tired, overweight, physically unattractive public official is not as appealing to the viewer-voter as a young, good looking, vigorous politician who can capture the public's vote with an assist from his nonverbal attraction (Knapp, 1972). Television tends to transform political candidates into actors and the eligible electorate into an audience. Hence, what matters most to voters is often not the substance of what the candidates say in televised debates but how well they say it and whether each candidate projects the image he strives to project (Lang, 1987).

Voters generally have social stereotypes about political candidates and physical attractiveness remains a significant one. Physically attractive candidates are generally inferred to have more desirable personality traits and to achieve greater vocational success than unattractive politicians. In the political arena, physical attractiveness is often stereotypically associated with certain attributes of an effective legislator like trustworthiness, credibility, and competence. These inferred attributes, which constitute the candidate's "image," exert important influence on people's 
voting decisions (Riggle, Ottati, Wyer, Kuklinski, \& Schwarz, 1992). According to Knapp (1972), television has helped to structure some of the public's nonverbal perceptions, and more and more political candidates recognize the tremendous influence these perceptions may have on the eventual election outcome. The current study's results suggest that viewers tend to be more persuaded by political candidates' nonverbal cues than their verbal arguments.

\section{Limitations}

While this research study provides reasonable evidence as to which characteristics viewervoters deem important when deciding whom to vote for during a gubernatorial election, there are several limitations that must be acknowledged. First, one of the limitations of this study is that it is a laboratory experiment. As noted earlier, there are several advantages to this type of method, not the least of which is control, which strengthens internal validity and helps to eliminate confounding variables. However, the nature of experiments can be considered a weakness due to the artificial environments in which they take place. According to Gunter (2000), "it has been argued that experiments provide evidence on the questions of whether the media can produce certain effects, though not necessarily demonstrate that such effects do actually occur in reality" (p. 252). In a more comfortable, familiar setting, participants may feel better about sharing personal information about themselves. Also, in the current study participants viewed video clips in an uncluttered environment under forced exposure conditions, which may not reflect actual television viewing behaviors. Nonetheless, this type of forced exposure aided in establishing causality between debater types and viewer responses.

In addition, it should also be noted that although the Cronbach's coefficient alphas of some of the verbal measures were considerably lower than what scales previously reported. However, this could be due to the fact that the scale was derived from portions of another scale which may 
limit reliability. The average reliability of the verbal scale was reported to be 0.610 , which is within the limits of acceptable reliability (Hair, Anderson, Tatham, \& Black, 1998). The fact that this is an average suggests that the scale may have been reliable for some of the messages, and not as reliable for others.

The length of the video clips shown to participants could also be considered a limitation to the study's validity. All 16 video clips were only one-minute long and might not have been a sufficient period of time for viewers to adequately understand and absorb each candidate's argument. This may also account for the viewers' lack of interest in the four topics discussed. It should also be noted that this study was conducted using convenience samples from several college classes, where the majority of students enrolled were in the 18 to 24 age demographic. In addition, the participants in the study represent a relatively small homogenous sample from a similar geographical location, and thus may have different attitudes, behaviors, and views than a sample selected elsewhere. Finally, since the participants in this experiment were relatively young, it is possible that this age group may not have taken the study as seriously as an older demographic may have.

On another note, the participants in this study were motivated volunteers (i.e., they received extra credit for participation) who due to the climate of their university and surrounding town may have felt the need to answer questions in a socially acceptable way.

Regardless of the experiment's limitations, there is no reason to believe that the findings from this study should not be similar for other segments of the population. Previous studies have shown that college students do not significantly differ from other samples in investigations of underlying psychological and attitudinal processes (Basil et al., 2002). Therefore, the generalizability of the attitudinal and voting intent data collected is not limited. 


\section{Future Research}

Future research should sample more verbal and visual messages in an attempt to replicate the results found here. This would provide more support for the persuasiveness of one type of message over the other. In addition, other segments of the population should be sampled to see what messages are more effective for different age groups. Future research on this topic should also include having participants watch longer gubernatorial debate clips to see if the same trend occurs when viewers have extended exposure to the candidates' arguments. It would be beneficial to assess viewers' attitudes by conducting interviews or surveys with them following the experimental procedures to specifically pinpoint what motivates them to vote for one candidate over another. Additionally, it would be interesting to see what other types of visual messages (billboards, flyers, photographs, paid television appearances, etc.) persuade viewers to vote for one candidate over another.

Additional study of the effects of verbal and visual cues on information processing should look at how voters use cognitive resources to search for and recall information about political candidates. This would provide communication researchers with a good indicated of how viewers store and retrieve the information from memory to form a final candidate preference and candidate evaluations (Meffert, Chung, Garst, \& Waks, 2003).

Finally, it should be noted that past gubernatorial campaigns have tended to rely solely on television in reading audiences. In keeping with today's social media trends, gubernatorial debates are now broadcast on social media websites and video-sharing forums like Facebook and Youtube.com. This provides viewers with the opportunity to share their opinions on candidates with others while viewing the debates. This is an interesting area for future study in regard to the dissemination and evolution of the messages transferred from person to person. The interpersonal 
communication that takes place in online forums is often more influential in behavior modification as they help to provide an environment in which behaviors are reinforced.

\section{Implications}

It is hard to disagree with the view that television has become an increasingly dominant factor in contemporary political communication. The transformation of political communication brought about by television has involved exposing the mass audience of voters to the sights and sounds of politicians speaking in a much wider range of contexts than ever before (Atkinson, 1984). Viewing televised debates increases political knowledge of candidates and reinforces viewers' commitments to their favorite candidates and to their participation in elections (An \& Pfau, 2004).

Televised debates between politicians on the national, state, and local levels are now an integral part of the American political scene. Political candidates who participate in debates do so because of their beliefs in the importance of the debates for winning the election (Lichtenstein, 1982). However, there is growing concern regarding the increasing dominance of image over substance and these developments are seen as threats to the democratic process. Certain facial features, ways of posing, clothing and backgrounds all contribute to or detract from a candidate's political demeanor (Rosenberg et al., 1991).

This research study constitutes an important step in establishing the political significance of the visual dimension of candidate presentation and how it shapes voters' preferences. Placed in the context of other work on candidate evaluation and voting behavior, research suggests that voters are not making choices on the basis of appropriate information on the candidates and the issues. This raises questions about the electoral process itself and the degree to which it serves its intended representative function (Rosenberg et al., 1991). Should audiences choose leaders based more on 
their performances on television, rather than on the strength of their arguments, one should seriously question if televised debates are feasible indicators of who "should" win elections. The legitimacy of televised debates depends on whether the electorate believes they convey the truth, instead of being just another part of the "highly visual" world of television (Lang, 1987). 


\section{REFERENCES}

Allen, J.L., \& Post, D.J. (2004). Source valence in assessing candidate image in a local election. Communication Research Reports, 21, 174-187.

An, C., \& Pfau, M. (2004). The efficacy of inoculation in televised political debates. Journal of Communication, 54, 421- 434.

Anderson, D. R., \& Burns, J. (1991). Paying attention to television. In J. Bryant \& D. Zillmann (Eds.), Responding to the screen: Reception and reaction processes (pp. 3-26). Hillsdale, NJ: Lawrence Erlbaum Publishers.

Andreoli, V., \& Worchel, S. (1978). Effects of media, communicator, and message position on attitude change. Public Opinion Quarterly, 42, 59-70.

Atkinson, M. (1984). Our master's voices: The language and body language of politics. New York: Metheun \& Company.

Baird, D. A. (2003). An emerging emphasis on image: Early press coverage of politics and television. American Journalism, 20, 1-19.

Baguley, T. (2004). An introduction to sphericity. Retrieved on July 12, 2010 from http://homepages.gold.ac.uk/aphome/spheric.html.

Basil, M. D., Brown, W. J., \& Bocarnea, M. C. (2002). Differences in univariate values versus multivariate relationships: Findings from a study of Diana, Princess of Wales. Human Communication Research, 28, 501-514.

Bennett, S. E. (1997). Why young Americans hate politics, and what we should do about it. Political Science and Politics, 30, 47-53.

Benoit, W. L., Brazeal, L. M., \& Airne, D. (2007). A functional analysis of televised U.S. Senate and gubernatorial campaign debates. Argumentation and Advocacy, 44, 75-89.

Berggren, N., Jordahl, H., \& Poutvaara, P. (2006). The looks of a winner: Beauty, gender and electoral success. Retrieved on July 7, 2010 from http://ftp://repec.iza.org/RePEc/Discussionpaper/dp2311.pdf

Bilandzic, H. (2003). Salient features of the television message. Paper presented at the International Communication Association.

Blais, A., \& Perrella, A. (2008). Systemic effects of televised candidates' debates. International Journal of Press/Politics, 13, 451- 464.

Boorstin, D. (1961). The Image. New York: Atheneum Publishers. 
Booth-Butterfield, S., \& Gutowski, C. (1993). Message modality and source credibility can interact to affect argument processing. Communication Quarterly, 41, 77-89.

Brownlow, S. (1992). Seeing is believing: Facial appearance, credibility and attitude change. Journal of Nonverbal Behavior, 16, 101-114.

Calfee, R. C. (1985). Experimental methods in psychology. Orlando, FL: Harcourt School Publishers.

Capella, J. B., \& Jamieson, K. H. (1997). Spiral of Cynicism: The press \& the public good. New York: Oxford University Press.

Cesario, J., \& Higgins, T. (2008). Making message recipients “feel right.” Psychological Science, $19,415-419$.

Chaffee, S. H., \& Schleuder, J. (1986). Measurement and effects of attention to news media. Human Communication Research, 13, 76-107.

Cohen, J. (1992). A power primer. Psychological Bulletin 112, 155-159

Davis, L. (1978). Camera eye-contact by the candidates in the presidential debates of 1976. Journalism Quarterly, 55, 431-455.

Eagly, A. H., \& Chaiken, S. (1983). Communication modality as a determinant of persuasion: The role of communicator salience. Journal of Personality and Social Psychology, 45, 241-256.

Eagly, A. H., \& Chaiken, S. (1993). The psychology of attitudes. FortWorth,TX: Harcourt Brace and Jovanovich.

Fazio, R. H. (1986). How do attitudes guide behavior? In R. M. Sorrentino \& T. R. Higgins (Eds.). Handbook of motivation and cognition (pp. 204 - 244). New York: The Guilford Press.

Glaser, J., \& Salovey, P. (1998). Affect in electoral politics. Personality and Psychology Review, $2,156-172$.

Glynn, C. J., Huge, M. E., \& Lunney, C. A. (2009). The influence of perceived social norms on college students' intention to vote. Political Communication, 26, 48-64.

Griffin, R.J., Neuwirth, K., Giese, J., \& Dunwoody, S. (2002). Linking the heuristic-systematic model and depth of processing. Communication Research, 29, 705-732.

Gunter, B. (2000). Media research methods: Measuring audiences, reactions and impact. Thousand Oaks, CA: Sage Publications. 
Hair, J.F. Jr., Anderson, R.E., Tatham, R.L., \& Black, W.C. (1998). Multivariate data analysis, (5 ${ }^{\text {th }}$ Edition). Upper Saddle River, NJ: Prentice Hall.

Herbeck, D., \& Mehltretter, S. (2005). A Beard and a Pasty Forehead: Collective Memory of the First Kennedy-Nixon Debate. Paper presented at the Annual Meeting of the International Communication Association, New York, NY.

Highlander, J. P., \& Watkins, L. I. (1962). A closer look at the Great Debates. Western Journal of Communication, 26, 39-48.

Johnson, E. (2007). Application of the theory of planned behavior to understand voting behaviors of the young electorate. Paper presented at the International Communication Association.

Jones, M. A., Mothersbaugh, D.L., \& Beatty, S. E. (2000). Switching barriers and repurchase intentions in services. Journal of Retailing, 79, 259-274.

Kane, P. E. (1966). Evaluating the Great Debates. Western Journal of Communication, 30, 89-96.

Knapp, M. L. (1972). Nonverbal communication in human interaction. New York: Holt, Rinehart and Winston, Inc.

Krosnick, J. (1988). The role of attitude importance in social evaluation: A study of policy preferences, presidential candidate evaluations and voting behavior. Journal of Personality and Social Psychology, 55, 196-210.

Krugman, H. E. (1971). Brain wave measures of media involvement. Journal of Advertising Research, 11, 3-9.

Lacy, D. \& Monson, Q. (2000). Anatomy of a third-party victory: Electoral support for Jesse Ventura in the 1998 Minnesota gubernatorial election. Paper presented at the Midwest Political Science Association.

Lang, A. (1995). Defining audio/video redundancy from a limited-capacity information processing perspective. Communication Research, 22, 86-115.

Lang, A., Geiger, S., Strickwerda, M., \& Sumner, J. (1993). The effects of related and unrelated cuts on television viewers' attention, processing capacity, and memory. Communication Research, 20, 4-29.

Lang, G. E. (1987). Still seeking answers. Critical Studies in Mass Communication, 4, 211-214.

Lichtenstein, A. (1982). Differences in impact between local and national televised political candidates' debates. Western Journal of Communication, 46, 291-298.

Louden, A. (2005). Researching non-presidential debates: A moment in time. Contemporary Argumentation and Debate, 26, 41-50. 
Meffert, M. F., Chung, S., Joiner, A. J., Garst, J. \& Waks, L. (2003). Motivated information search and candidate evaluations: On-line versus memory-based process models. Paper presented at the Annual Meeting of the International Communication Association, San Diego, CA.

McKinney, M. S., \& Carlin, D. B. (2004). Political campaign debates. In L. L. Kaid (Ed.), Handbook of Political Communication Research (pp. 203-234). Mahwah, NJ: Lawrence Erlbaum Associates.

McCroskey, J. C., \& McCain, T. A. (1974). The measurement of interpersonal attraction. Speech Monographs, 41, 261-266.

Miller, M. D., \& Levine, T. R. (1996). Persuasion. In M. B. Salwen \& D. W. Stacks (Eds.), An integrated approach to communication theory and research (pp. 261-276). Mahwah, NJ: Lawrence Erlbaum Associates.

Nebergall, R. (1966). The social judgment-involvement approach to attitude and attitude change. Western Speech, 30, 209-215.

Neuwirth, K., Frederick, E. \& Mayo, C. (2002). Person-effects and heuristic-systematic processing. Communication Research, 29, 320-359.

O’Keefe, D. J. (2003). Message properties, mediating states, and manipulation checks: Claims, evidence and data analysis in experimental persuasive message effects research. Communication Theory, 13, 251-274.

Ohanian, R. (1990). Construction and validation of a scale to measure celebrity endorsers' perceived expertise, trustworthiness, and attractiveness. Journal of Advertising, 19, 39-52.

Oskamp, S., \& Schultz, P. W. (1998). Applied social psychology (2nd ed.). Upper Saddle River, NJ: Prentice Hall.

Paek, H., Pan, Z., Sun, Y., Abisaid, J., \& Houden, D. (2005). The third-person perception as social judgment: An exploration of social distance and uncertainty in perceived effects of political attack ads. Communication Research, 32, 143-169.

Patterson, S.C. \& Caldeira, G. A. (1983). Getting out the vote: Participation in gubernatorial elections. The American Political Science Review, 77, 675-689.

Perloff, R. M. (1993). The dynamics of persuasion. Hillsdale, NJ: Lawrence Erlbaum Associates.

Pinkleton, B. E., \& Austin, E.W. (2004). Media perceptions and public affairs apathy in the politically inexperienced. Mass Communication \& Society, 7, 319-337. 
Reeves, B. \& Geiger, S. (1994). Designing experiments that assess psychological responses to media messages. In A. Lang (Ed.), Measuring psychological responses to media messages. Hillsdale, NJ: Lawrence Erlbaum Associates.

Reynolds, O. T. (1968). American public address and the mass media. Western Journal of Communication, 32, 44-49.

Richmond, V. P., McCroskey, J. C., \& Johnson, A. E. (2003). Development of the nonverbal immediacy scale (NIS): Measures of self- and other-perceived nonverbal immediacy. Communication Quarterly, 51, 502-515.

Riggle, E. D., Ottati, V.C., Wyer, R. S. Jr., Kuklinski, J., \& Schwarz, N. (1992). Bases of political judgments: The role of stereotypic and nonstereotypic information. Political Behavior, 14, 67-87.

Rosenberg, S.W., Kahn, S., Tran, T., \& Le, M. (1991). Creating a political image: Shaping appearance and manipulating the vote. Political Behavior, 13, 345-367.

Rosenberg, S.W., Bohan, L., McCafferty, P., \& Harris, K. (1986). The image and the vote: The effect of candidate presentation on voter preference. American Journal of Political Science, 30, 108-127.

Rubin, R., Palmgreen, P., \& Sypher, H. (2004). Communication research measures. Mahwah, NJ: Lawrence Erlbaum Associates.

Salkind, N.J. (2004). Statistics for people who (think they) hate statistics. Thousand Oaks, CA: Sage Publications.

Seiter, J. S., Weger, H., Kinzer, H. J., \& Jensen, A. S. (2009). Impression management in televised debates: The effect of background nonverbal behavior on audience perceptions of debaters' likeability. Communication Research Reports, 26, 1-11.

Shapiro, M. A. (2002). Generalizability in communication research. Human Communication Research, 28, 491-500.

Sherif, M. \& Hovland, C.I. (1961). Social judgment: Assimilation and contrast effects in communication and attitude change. New Haven, CT: Yale University Press.

Sherif, C.W., Sherif, M., \& Nebergall, R.E. (1965). Attitude and attitude change: The socialjudgment-involvement approach. Philadelphia, PA: W.B. Saunders.

Sternthal, B., Phillips, L.W., \& Dholakia, R. (1978). The persuasive effect of source credibility: a situational analysis. Public Opinion Quarterly, 42, 285-315 
Stevens, J. P. (2002). Applied multivariate statistics for the social sciences $\left(4^{\text {th }}\right.$ ed.). Mahwah, NJ: Lawrence Erlbaum Associates.

Sullivan, D.G., \& Masters, R.D. (1998). “Happy warriors”: Leaders' facial displays, viewers' emotions, and political support. American Journal of Political Science, 32, 345-368.

Teven, J. (2008). An examination of perceived credibility of the 2008 president candidates: Relationships with believability, likeability, and deceptiveness. Human Communication, 11, 391-408.

Till, B. D., \& Shimp, T. A. (1998). Endorsers in advertising: The case of negative celebrity information. Journal of Advertising, 27, 67-82.

Tims, A. R. (1986). Family political communication and social values. Communication Research, $13,5-17$.

Unknown. (2005). Gas prices around the world. CNN Money. Retrieved June 16, 2010 from $\mathrm{http} / / /$ money.cnn.com/pf/features/lists/global_gasprices/

Waheed, M., \& Chung, S. (2008). Heuristic and systematic biased processing of political messages: Effects of candidate preference and the level of interest in politics on attitudes toward issues. Conference paper presented at the Annual Meeting of the National Communication Association, Washington, D.C.

White, T. H. (1961). The making of the President 1960. New York: Atheneum.

Wimmer, R. D., \& Dominick, J. R. (2006). Mass media research: An introduction. Belmont, CA: Thomas Wadsworth.

Zhang, L., \& Pinkleton, B. (2009). Internet use, cynicism and skepticism in young citizens' attitudes towards political decision making. Conference paper presented at the Annual Meeting of the International Communication Association, Chicago, IL. 


\section{APPENDIX A}

\section{VERBAL ARGUMENT SCALE}

The participant was asked to indicate the degree to which he or she agrees or disagrees with the following statements as they apply to each gubernatorial candidate on a Likert-scale of one to five, with five meaning the participant strongly agrees and one meaning the participant strongly disagrees.

Strongly Disagree

Strongly Agree

\begin{tabular}{|c|c|c|c|c|}
\hline 1) He (she) is loud. & 1 & 2 & 3 & 4 \\
\hline 2) He (she) uses powerful language. & 1 & 2 & 3 & 4 \\
\hline 3) He (she) has a large vocabulary. & 1 & 2 & 3 & 4 \\
\hline 4) $\mathrm{He}$ (she) is conversational. & 1 & 2 & 3 & 4 \\
\hline 5) I can understand him/her clearly. & 1 & 2 & 3 & 4 \\
\hline
\end{tabular}




\section{APPENDIX B}

\section{PHYSICAL ATTRACTION SCALE}

Please indicate the degree to which you agree or disagree with the following statements as they apply to each gubernatorial candidate on a scale of one to five, with five meaning you strongly agree and one meaning you strongly disagree.

Strongly Disagree

1) I think he (she) is quite handsome (pretty).

2) $\mathrm{He} /$ she is somewhat ugly.

3) He (she) is very sexy looking

4) I find him (her) very attractive physically.

5) I don't like the way he (she) looks.

6) $\mathrm{He} /$ she is not very good looking

\begin{abstract}
12
\end{abstract}
12

12

12

12

12
Strongly Agree

$\begin{array}{lll}3 & 4 & 5 \\ 3 & 4 & 5 \\ 3 & 4 & 5 \\ 3 & 4 & 5 \\ 3 & 4 & 5 \\ 3 & 4 & 5\end{array}$




\section{APPENDIX C}

\section{ATTITUDE TOWARD THE COMMUNICATOR}

On the scales below, indicate your feelings about the communicator.

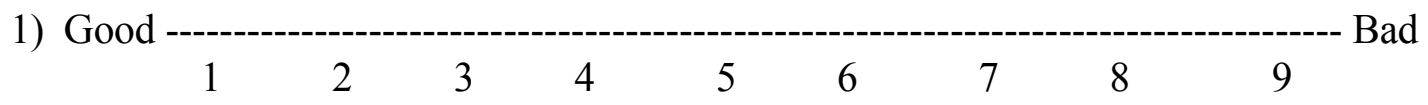

2) Favorable

Unfavorable

$\begin{array}{lllllllll}1 & 2 & 3 & 4 & 5 & 6 & 7 & 8 & 9\end{array}$

3) Positive-

$\begin{array}{lllllllll}1 & 2 & 3 & 4 & 5 & 6 & 7 & 8 & 9\end{array}$




\section{APPENDIX D}

\section{BEHAVIORAL INTENTION}

On the scales below, indicate how likely you are or how strong your intention is to vote for each gubernatorial candidate.

1) Likely

$\begin{array}{lllllllll}1 & 2 & 3 & 4 & 5 & 6 & 7 & 8 & 9\end{array}$

2)

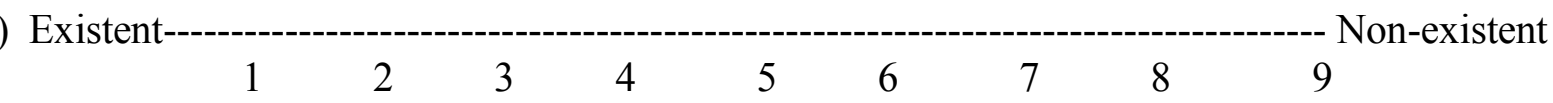

3) Probably-

$\begin{array}{lllllllll}1 & 2 & 3 & 4 & 5 & 6 & 7 & 8 & 9\end{array}$

4) Possible

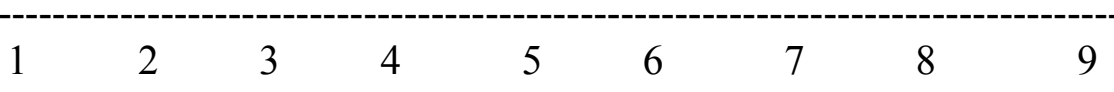

-Impossible

5) Certain-

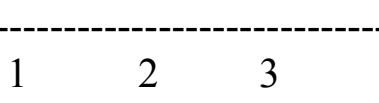

$4-5$

5

6

$7 \quad 8$

---Uncertain

uld

6) Definitely would

$\begin{array}{lllllll}- & 3 & 4 & 5 & 6 & 7 & 8\end{array}$

7) Certain chance

1

$2 \quad 3$

$\sqrt{2}$

$\begin{array}{lllll} & & & & \\ & 6 & 7 & 8 & 9\end{array}$




\section{APPENDIX E}

\section{STIMULI PRE-TEST}

In this experiment you are going to watch a series of short (60 second) debate clips. When you are finished answering the questions on this page, please turn your packet to the next page. This will signal to the researcher that you are ready to proceed.

After viewing each clip, you will be asked to indicate on a scale from 1-7 how effective you felt each debater was. For example, on the first pair of adjectives, if you thought the debater was very physically attractive, give it a 1 . If you thought the debater was very physically unattractive, give it a 7. If you thought the debater's physical features were somewhere in between, give it a 2, 3, 4, 5 or 6.

For each section, answer by circling the numbers - DO NOT CIRCLE THE WORDS.

Attractive

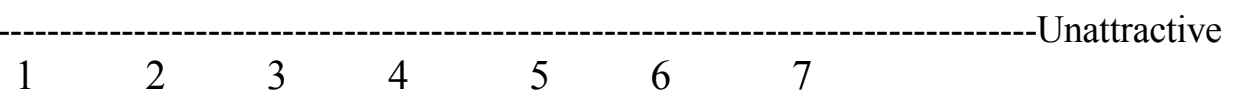

Not Good looking

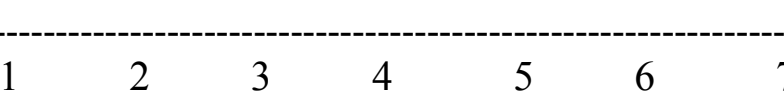

-Good looking

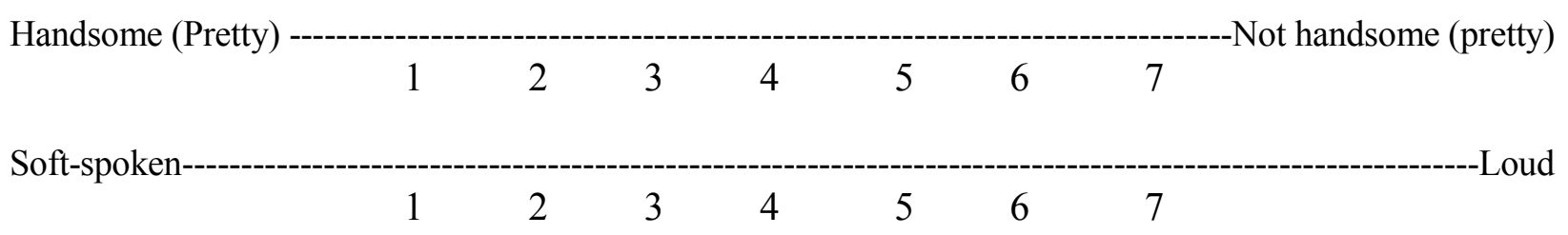

Speaks powerfully

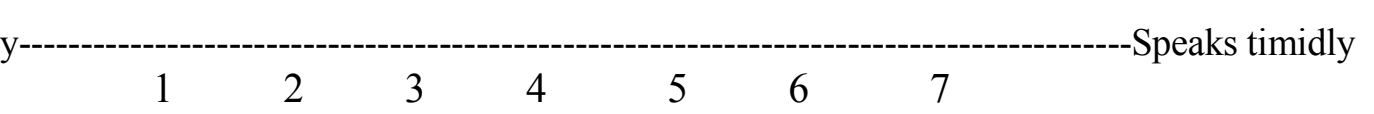

Poor vocabulary

$\begin{array}{llll}1 & 2 & 5 & 5\end{array}$

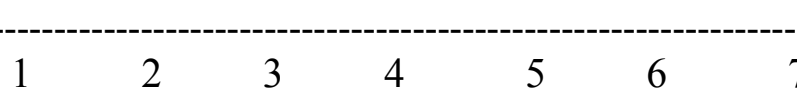
Easy to understand-

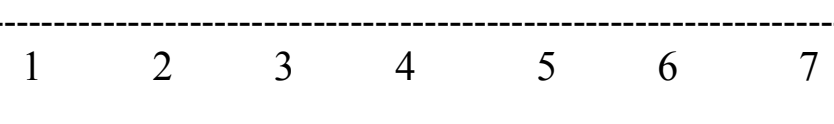
Monotone voice

$\begin{array}{lllllll}1 & 2 & 3 & 4 & 5 & 6 & 7\end{array}$
Conversational speaker

12

Rarely smiles

-Smiles often 


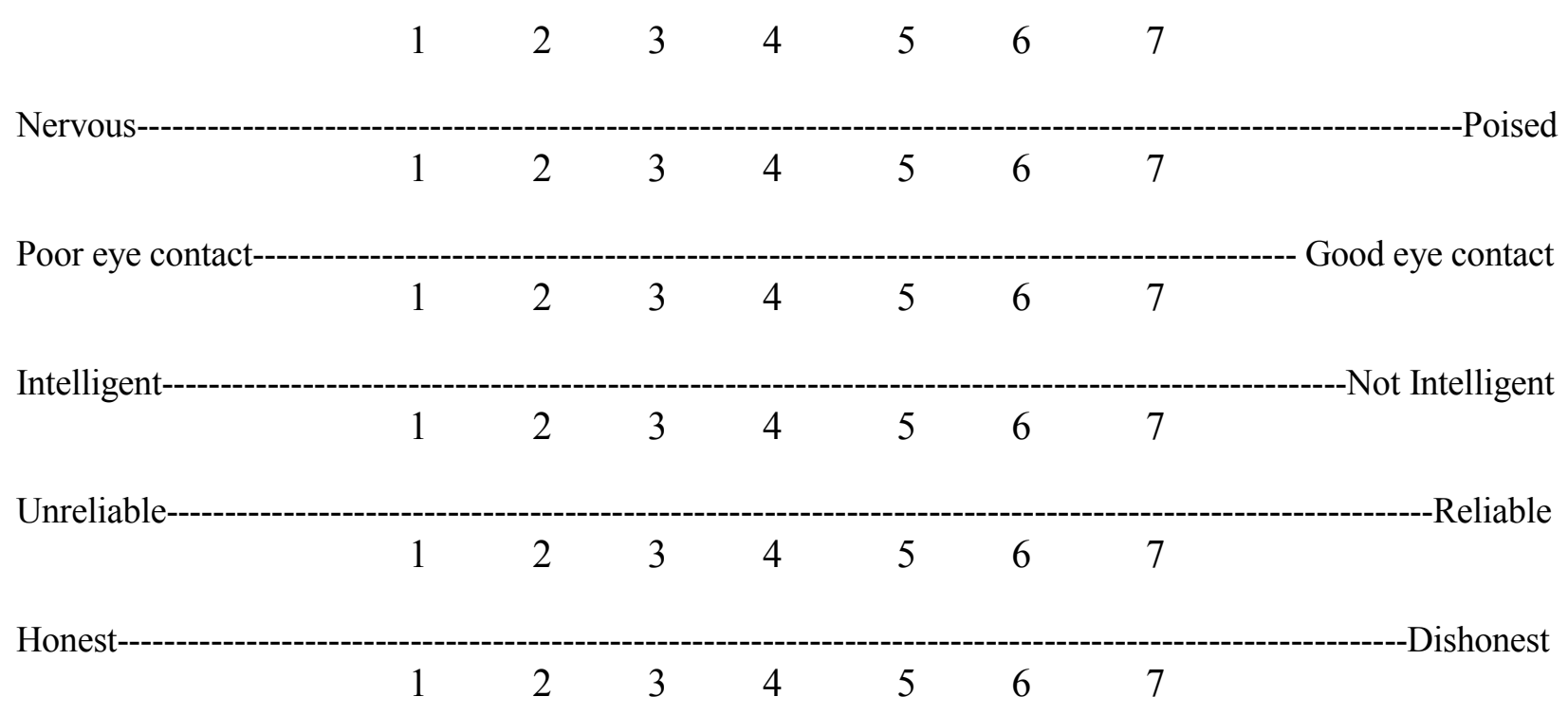


APPENDIX F

IRB APPROVAL

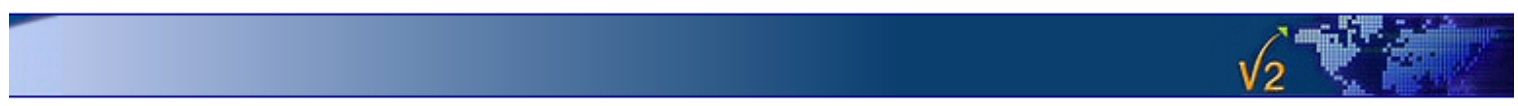

IRB PROTOCOL - Details

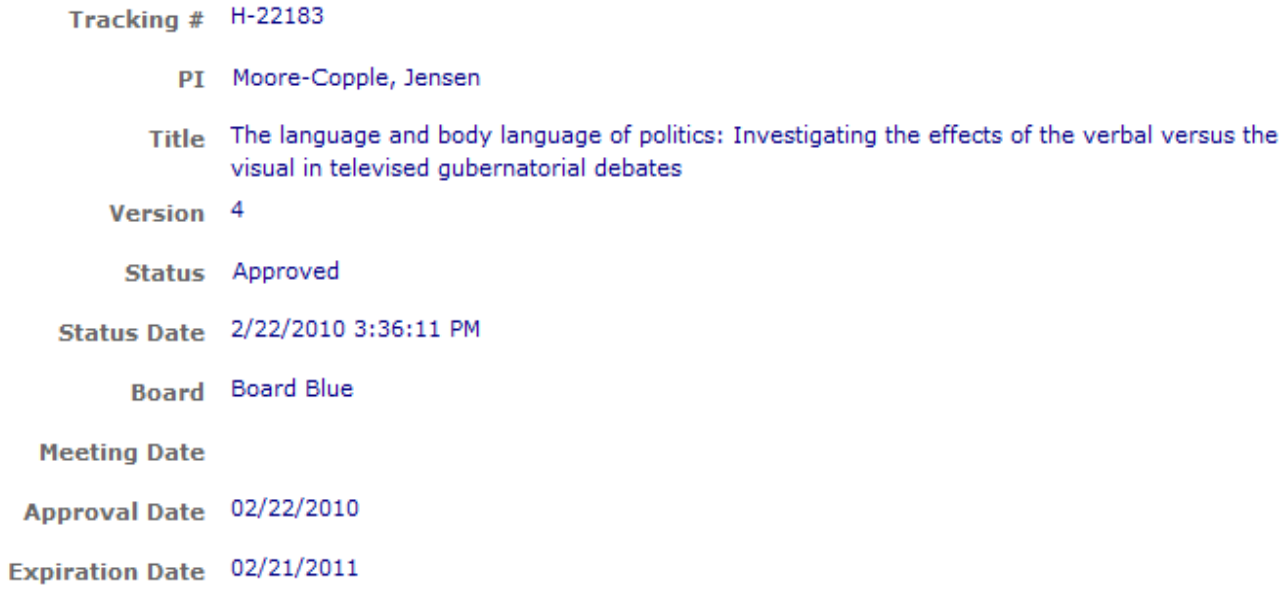




\section{APPENDIX G \\ P.I. Reed School of Journalism \\ Extra Credit Plan for Student Research Participation}

May 10, 2007

May 10,2007

Please note that extra credit for participation will be offered only in those instances where it is deemed necessary to help gain the numbers or types of students for valid results and in those courses where a set standard grading scale is used to assign final grades (e.g. 90-100\% of total points $=\mathrm{A}$ ). In other words, professors who teach classes in which final grades are assigned on a curve should not allow extra credit points for research participation. To do so unfairly penalizes those students who cannot or who choose not to participate in extra credit activities.

\section{Procedures}

Students are told about extra credit opportunities through their professors, who have agreed to allow extra credit for participation. Students may be asked to participate during class or to attend a session outside of the classroom on their own time (e.g. in the case of controlled experimental research, where students are exposed to various types of advertising or public service messages and asked to respond to those).

\section{External locations}

For extra credit outside of class time, students are asked to "sign in" when they arrive at a lab or $\log$ on to the Web using their own computer or the one provided by the experimenter. This is the only way their names are known, and their names are not associated with any of the experimental responses. For studies that need exposure to multiple experimental sessions, student names may need to be associated with their responses for tracking purpose only. All personally identifying information will be promptly disposed upon data analyses. Of course, all procedures will have been submitted to and approved by the IRB.

\section{Classroom participation}

In classroom settings, where professors have approved the extra credit offering, students turn in their responses (e.g. to an anonymous survey that has ) and are asked to sign a separate sheet on the other side of the room after doing so. Again, all personally identifying information will be properly disposed after data analyses, and all procedures will have been submitted to and approved by the IRB.

\section{Points allowed}

Extra credit will range from 0.5 to 2 percent of the maximum point total a student can earn in a class, depending on the participating professor's desire and the time the participant is expected to spend.

\section{Alternative assignments}

Students who choose not to participate in the research must be offered alternative forms of extra credit by their participating professors. This will be communicated to each professor who agrees to 
allow their students extra credit to participate in the research and will be communicated to the students when the research opportunity arises. (In addition, once the IRB has approved the School of Journalism extra credit plan for research participation, all SOJ faculty, including adjuncts, will be given a copy of the policy.)

The options for extra credit must be equivalent to the points awarded for participation in the research and to the amount of time, thought, and effort required of it. Professors will be given the following as alternative extra credit options:

- having students seek out and view a particular type of ad (magazine, TV, radio, Internet, newspaper) and answer basic questions that are relevant to issues being studied (e.g., target audience, design/image elements, message components, appeal types ....)

- having students seek out and view or read a particular news article or story in two different media outlets and compare / contrast them in terms of topics being studied and discussed in class

- $\quad$ having students use existing WVU databases (e.g. Mediamark) to learn about a particular audience, mass medium, product line or brand

- having students develop a limited annotated bibliography on a particular course subject of interest to the student and the professor

- having students submit a one or two-page summary of a relevant journal article

- having students attend a guest speaker or lecture that is being hosted by the School or by some other University department on a topic relevant to the course and writing a one-page paper on what the student learned relevant to the course or the profession. 


\section{APPENDIX H \\ WestVirginiaUniversity。}

CONSENT AND INFORMATION FORM

OMR ICF

Principal Investigator:

Department:

Tracking Number:

Study Title:

The language and body language of politics: Investigating the effects of the verbal versus the visual in televised gubernatorial debates

Co-Investigator(s):

Fernandes, Nicole

Contact Persons

In the event you experience any side effects or injury related to this research, you should contact Dr. _Jensen Moore-Copple_ at (304) 293-3505 ext 5427 or Nicole Fernandes at (304) 932-6585.

For information regarding your rights as a research subject, to discuss problems, concerns, or suggestions related to the research, to obtain information or offer input about the research, contact the Office of Research Compliance at (304) 293-7073.

Introduction

You, have been asked to participate in this research study, which has been explained to you by Dr. Jensen Moore-Copple, PhD, and Nicole Fernandes, BSJ.

This study is being conducted by Dr. Jensen Moore-Copple, PhD, and Nicole Fernandes, BSJ, in the Department of Journalism at West Virginia University. This research is being conducted to fulfill the requirements for a master's thesis in Journalism in the Department of Journalism at West Virginia University, under the supervision of Dr. Jensen MooreCopple, PhD.

Purposes of the Study 
The purpose of this pre-test study is to learn more about viewers' attitudes toward televised gubernatorial debates. Data collected from this pre-test will help the researcher determine which clips to use for the final experiment. WVU expects to enroll approximately 100 subjects.

\section{Description of Procedures}

This study involves viewing a series of forty 60 -second televised gubernatorial debate clips and completing a series of questions about message content following each clip and will take approximately $\mathbf{5 0}$ minutes for you to complete. You will be asked to fill out a questionnaire regarding demographic information. This will take approximately 10 minutes to complete. You do not have to answer all the questions. You will have the opportunity to see the questionnaire before signing this consent form. Overall, the entire study will take approximately 1 hour.

\section{Risks and Discomforts}

There are no known or expected risks from participating in this study, except for the mild frustration associated with answering the questions.

\section{Alternatives}

You do not have to participate in this study.

There are no other alternatives at the present time.

\section{Benefits}

You may receive the direct benefit of learning more about the importance of televised debates in the realm of political communication. The knowledge gained from this study may eventually benefit others.

\section{Financial Considerations}

There are no special fees for participating in this study, but extra credit points will be awarded for this class. There will be other extra credit opportunities available during this semester.

\section{Confidentiality}

Any information about you that is obtained as a result of your participation in this research will be kept as confidential as legally possible. Your research records and test results, just like hospital records, may be subpoenaed by court order or may be inspected by federal regulatory authorities without your additional consent. In any publications that result from this research, neither your name nor any information from which you might be identified will be published without your consent.

Voluntary Participation

Participation in this study is voluntary. You are free to withdraw your consent to participate in this study at any time. Refusal to participate or withdrawal will not affect 
your employee status at West Virginia University or your class standing or grades and will involve no penalty to you.

In the event new information becomes available that may affect your willingness to participate in this study, this information will be given to you so that you can make an informed decision about whether or not to continue your participation.

You have been given the opportunity to ask questions about the research, and you have received answers concerning areas you did not understand.

Upon signing this form, you will receive a copy.

I willingly consent to participate in this research.

Signature of Subject or Subject's Legal Representative

Printed Name

Date

Time

Subjects Legal Representative

The participant has had the opportunity to have questions addressed. The participant willingly agrees to be in the study.

Signature of Investigator or Co-Investigator

Printed Name

Date

Time

Co-Investigator

Tracking \#: H-22183 Page 4 of 4

Approved On: 02/22/2010 Initials Date

Valid Through: 02/21/2011

Last Amended: N/A 


\section{APPENDIX I}

\section{DEBATE SCRIPTS}

\section{HIGH VERBALSUAL/HIGH VISUAL - CHRISTINE GREGOIRE (Washington):}

"And so when I came into office, we began looking at how can we reform the education system in the state of Washington and let me tell you what we've done: we've said we're not going to be dead last when it comes to early childhood education; our kids deserve better. We're going to get a world class early childhood education program in the state of Washington, which we've begun now with a non-profit called "Drive by Five," with one of the pilots right here in Yakima to show that every child when they're ready to learn and when they get into kindergarten will succeed in school and succeed in life. To give our children a little bit more boost, we are now implementing all-day kindergarten and making sure that's happening. And we're making sure we have the best teachers in that classroom with national board certification. And we're turning our standards on math and science which is the language of competition to international standards where they really should. And where the doors of higher education were being closed when I came into office, we've opened them. And we've also said to high school students if you want a good family wage job get involved in a trade. We'll guarantee you apprenticeship and we've doubled the numbers."

\section{HIGH VERBAL/HIGH VISUAL - DINO ROSSI (Washington):}

"It's like the James Fonda China Syndrome era. And the reality is that nuclear power is being used all over the world. You go to France and it's about $80 \%$ of their power. Any time there's a plant that's offered up, people bid to have it in their community. We're building petrification plants in Tri-Cities which take radioactive sludge and turn it into glass which you can store forever. The technology is so far advanced. We need to be going after every bit of energy that we can put up on the grid. One of the reasons why we at industry come to Washington State early on is because the cost of power was low. The reason the incumbent didn't pick up the phone is because she was afraid of what some of her supporters in certain parts of the state would say if she brought AREVA to Washington State. Well AREVA is already in Washington State; this would have just added to the size of the operation they have in Tri-Cities. And this is really a shame. You know Tri-Cities now have to figure out how their financial situation is going to survive because of that inaction."

\section{HIGH VERBAL/HIGH VISUAL - JOHN HOEVEN (North Dakota):}

"We're now in a position to provide real tax relief. Furthermore on this issue of out of state, over $90 \%$ of the tax benefits are in-state and we emphasize property tax relief which helps low income and fixed income the most. I'm sorry you're just not credible when it comes to tax relief. You voted for $\$ 1.75$ billion in tax increases and you've already spent the surplus multiple times so that you aren't able to provide tax relief. We've put forth a solid plan that will provide $\$ 300$ million dollars in direct property tax relief, will provide income tax relief to the citizens of North Dakota as well and it provides $20 \%$ income tax relief to the people in the lower brackets which are about $70 \%$ of the people and only $8 \%$ in the top brackets. So it is weighted toward lower income individuals and it reforms and provides more education funding as well so this is ....." 


\section{HIGH VERBAL/LOW VISUAL - JAY NIXON (Missouri):}

"Clearly we need to have a broad based energy policy. That policy needs to include all the options out there: wind, air, solar, includes nuclear as an option. But we must protect consumers and see what was passed to make sure consumers are protected. It must be a part of any plan that would leave that as an option. We can't allow just an investor in utilities to profit off of Missourians. If we were to make that important step to provide that base we'd want to make sure that consumers were protected and if power was wielded outside the state we benefited from that. But there's a long way between the finish line there to make sure that consumers are protected and bills go down. We've also got a lot we can do on conservation, on alternative energy, on wind, on solar, broad base on biofuels, on ethanol, on biodiesel. We're blessed here in Missouri with a myriad of options. The one option is inaction. The one option is to be where the country is, reliant on Middle East oil, reliant on other places. When I'm your governor I'm not going to be like California and have a rolling blackout and the country relying on Saudi Arabia. We're going to get started real soon, direct up with all options, incentivize and work to make sure that we're an energy independent state on all sources."

\section{LOW VERBAL/HIGH VISUAL - Kenny Hulshof (Missouri):}

"I'm for all of the above strategies - conservation, alternatives, responsible exploration. When $70 \%$ of the country did not support looking at the 2000 acre area in Alaska I was for it because we could do it responsibly. Deep sea drilling. Now of course it seems that the country is beginning to change their minds and moods as far as looking at responsible exploration of our own resources. Yes to nuclear, yes to wind, yes to solar, yes to hydroelectric. In fact, we've begun working already; we've built the locks and dams on the Upper Mississippi River. One of those dams will be capable to have hydroelectric power. We're going to work with the state of Illinois to make that happen. We have wind farms in the state of Missouri and we've put forth an energy plan to look at $\$ 1.4$ billion barrels of oil, of heavy oil, that we have here in the state of Missouri including a refinery... building it here in our state."

\section{LOW VERBAL/LOW VISUAL - Jerry Brady (Idaho):}

"A governor can't do anything about the price of gasoline - after all it's set in the international market and determined by OPEC and Venezuelans. But in fact what happened in Idaho last month was that our gas prices were 60 percent more than the people in Ohio, Indiana, or Minnesota. Now why was that? Because we have one pipeline which comes to us from Salt Lake up through South Central Idaho and there are only two companies that put into that, put their gasoline, into that pipeline. We are getting price gouged by those refiners and by distributors. And we could take legal action against them. I would look into doing that. The attorney general should be doing that right now. But you know Congressman Otter has received the maximum contribution from one of the refiners that puts the gasoline into that pipeline in the first place. He's received contributions from all of the distributors of that gas. So how are you going to take after price gouging in gasoline which means so much to people in this state if you've already been contributed to by them and they're on your side? I am for the ordinary person - I want people to be able to travel in a way that is economical and that will get them to work and take care of their families." 
HIGH VERBAL/HIGH VISUAL - BUTCH OTTER (Idaho):

“......our policy in the early 90's. Perhaps he's changed his mind on this too because he said the problem with oil is there's not a scarcity of oil people just won't pay the price that they should be paying for oil. In fact Mr. Brady even went on to say why we should drill for our own oil? I am against ANWIRE, I am against drilling in the offshore, I am against drilling in the Gulf, and I am against drilling on public land. Let us buy our oil from Saudi Arabia. Why should we be using up our own reserve when we should be buying our oil from Saudi Arabia? So now we're hearing that its OPEC's fault when in fact once again Mr. Brady opined in his own newspaper that we should be buying the oil from the very people that he now points the finger of demonism at."

\section{HIGH VERBAL/LOW VISUAL - SONNY PERDUE (Georgia):}

"I think there's been too much pressure and too much emphasis on the high stakes testing yes and that's why I recommend and we are promoting a pre-diagnostic and a post-diagnostic test on a regular basis to help students and their parents know where they are and in the process know what they've learned in that particular area. The fact is we have moved off the bottom in SAT scores because the business community looks at that. The highest SAT scores in the state's history because we're paying attention, the highest graduation rates, 7935 more students are going to graduate this last year than they would have four years ago under the Barnes Taylor administration because we're focusing on students with a rigorous curriculum, putting graduation coaches, lowering class sizes by $65 \%$ and we the highest paid teachers in the Southeast.

\section{HIGH VERBAL/LOW VISUAL - MARK TAYLOR (Georgia):}

"Billion dollars worth of cuts to education - he says it's not true but it's documented. Our SAT scores actually fell last year, they didn't go up. It is a situation where the people of Georgia have to realize that education excellence, a focus on education, begins at the office of governor and for the first three years of Governor Perdue's administration it is obvious from the fact that his net worth has doubled in the last 4 years, its obvious from the Disneyland deal, the $\$ 100,000$ tax break for himself and no one else and now the loss of Okey Woods that Governor Perdue's priorities have been on himself; they have not been on the education of Georgia's kids. That's why I'm proposing to stop his cuts to education, to lower class sizes in Georgia and to work as other states have worked to get flexibility out from under No Child Left Behind so we'll have more time on task - teacher and student together."

\section{HIGH VERBAL/LOW VISUAL - DONALD CARCIERI (Rhode Island):}

"If it only 250 over the next two years that'll be the best we've looked at in years. Uh we've looked at projections and by the way these are only projections. What he's talking about is running out the assumptions on what people would like to spend. We always spend more than we have in previous years; there are never any cuts in the budget. What I've been working for the last four years is to slow down the growth rate of spending. Since I've been governor the year over year increases in spending are down to $4 \%$ on average - that's half what they were for the prior four years. Because of that, and because of the big audit which is saving a quarter of a billion dollars already and another quarter of a billion dollars in the next five years, we're able to give tax relief, we're able to phase out the car tax, we're able to give the kinds of property tax, we're able to give inventory taxes, cut the capital gains tax. All these things will set the stage for us to continue to grow economically." 


\section{LOW VERBAL/HIGH VISUAL - JOE KENNY (New Hampshire):}

"You could say that when I went to the University of New Hampshire I worked my way through college. At that time it cost less than $\$ 20,000$ to have that college experience. Today it would be about $\$ 84,000$ for me to go to the University of New Hampshire. We're pricing our kids who live in-state from going to the University of New Hampshire. Luckily we have a jewel and it's called our technical college programs where you can basically go ahead for $\$ 3,000$ a year for your tuition and you can go ahead and get your associate's degree. It's very affordable, it's an excellent fooder chain, fooder, uh food chain and then to the next level which is a four year program at the University of New Hampshire. But the reality is if you look at what's going on in the University of New Hampshire system is that you have a lot of high priced people there. You have a lot of administration. And as someone who knows someone who serves on the University Of New Hampshire Board Of Trustees, they should be really looking at the university system and seeing where they can come up with their cost savings so they can lower the rates of the insurance, or the rates of the tuition on these students."

\section{LOW VERBAL/HIGH VISUAL - JOHN LYNCH (New Hampshire):}

"I issued an executive order directing state agency heads to reduce their energy usage and also when they purchase equipment or they purchase automobiles to make sure they are energy efficient. I've also set our state I think on a path to a new energy future where $25 \%$ of our energy will come from renewable sources by 2025. It's perfect for New Hampshire. We have an abundance of biomass and timber. It will create jobs; it's environmentally friendly and over time it will help stabilize the cost of energy because we're diversifying our sources. Additionally we see a lot of important initiatives going on. There is a new wind power project in Lemster that will produce a power plant of 25 megawatts capable of heating 10,000 homes. There are similar projects going on in the North Country, both with wind and biomass. So our state I think is becoming an energy leader with regard to renewable energy."

\section{LOW VERBAL/HIGH VISUAL - JOHN HUNTSMAN (Utah):}

"I think we've knocked it right out of the ballpark - over the last three years there's been an increase in public education spending. A $40 \%$ increase when you look at money to educators, which I think is the most important part of the equation right now. I want to see educators on a pedestal. I want to see kids aspire to be educators like my grandfather was. There's been a $19 \%$ increase in teacher compensation, a $23 \%$ increase in new teacher compensation so that's a billion dollars total that nobody thought we would have that we did because the economy was doing very well. So you can't find another state in America by the way that even comes close to those numbers in terms of our commitment the last two to three years for public education. So I'd say we've been able to prove a very important premise and that is if the economy remains strong and if we do a good job in terms of maintaining a competitive environment for capital, for entrepreneurs, and for the free market system, we're going to do what needs to be done on the public education side."

\section{LOW VERBAL/LOW VISUAL - BOB SPRINGMEYER (Utah):}

"John mentioned the New York Times article. The Tribune had an article recently that said that the state has increased their fleet of SUVS and gas guzzling four wheel drives by $12 \%$. John's talk is 
great but it's in the performance that really counts. Now on SYNFUELS, I'd done a lot of work over the years so I'm somewhat familiar with that area. I support, with some skepticism quite frankly, Congressman Matheson's proposal and if I'm governor I would agree to allow a test site to be done, assuming that it meets all the environmental requirements and especially that there not be an exemption from the Clean Water Act. But if I have any influence on the direction of it, I'd really rather see that investment in a demonstration site be spent on sequestering carbon for coalfired plants because I really think coal is really more important in this state than natural gas."

\section{LOW VERBAL/LOW VISUAL - BRIAN SCHWEITZER (Montana):}

"Electricity generation has increased more during the last three and a half years than in the previous sixteen years combined and yes coal production is up as well as compared to the previous sixteen years combined including when my opponent was a state senator. They increased coal production by one million tones and we've increased it by three million tones already and now we're opening the Signal Peak Coal Mine which will add to Montana's coal production by 35\%. Yes I have attracted companies to come to Montana, attracted them from Australia, attracted them from Ohio and I am actively pursuing all forms of energy - that's why we've passed the wind energy bill and the transmission bill. That's why we were supporting oil production and coal production. We have increased oil production in Montana at the fastest new rate in the history of Montana - we're proud of that record."

\section{LOW VERBAL/LOW VISUAL - ROY BROWN (Montana):}

“.....A national energy leader in energy development in this state. But all we hear is a lot of talk. I say develop energy now, develop it here and develop it with Montana workers. You know I am an all of the above kind of guy. I believe in oil, gas, coal, solar, wind, geothermal, all of those things. And we've heard a lot of talk about all of them. But the fact is I disagree with Stan - the real reason why none of these things are getting done is because of the people that have been appointed to the boards that will never approve anything that the governor is talking about. Do you know that oil production in Montana right now is going down? The governor keeps saying how our oil production is just going through the roof. Oil production is down, our rigs are leaving the state, yes Montana is on the move and all our rigs are leaving our state for North Dakota." 


\section{APPENDIX J}

\section{EXPERIMENT QUESTIONNAIRE}

Please indicate with the following statements your attitudes toward the topics presented in the clips:

1) I feel that education reform has been long overdue in this country.

Strongly Agree-

Disagree

$\begin{array}{lllllllll}1 & 2 & 3 & 4 & 5 & 6 & 7 & 8 & 9\end{array}$

Strongly

2) I feel that in order to address the issue of climate change we have to implement energy reform policies.

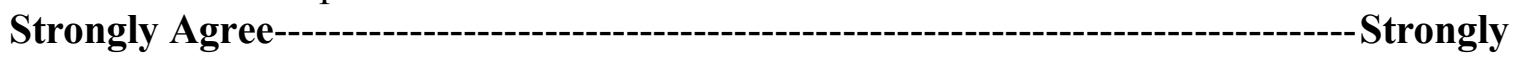

Disagree

$\begin{array}{lllllllll}1 & 2 & 3 & 4 & 5 & 6 & 7 & 8 & 9\end{array}$

3) A key initiative on the economic agenda should be finding ways to lower gas prices.

Strongly Agree-

Strongly

Disagree

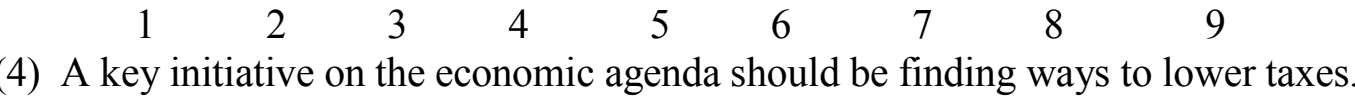

Strongly Agree

Disagree

Strongly

$\begin{array}{lllllllll}1 & 2 & 3 & 4 & 5 & 6 & 7 & 8 & 9\end{array}$

Attitude Toward the Debater

Please indicate with the following statements what you think about the debater you just saw

1) Overall, what is your impression of the debater?

Very good-

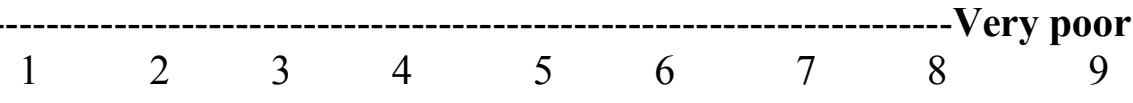

2) To what degree did you feel favorably toward the debater?

Not favorable-

$\begin{array}{rrrrrrrrr}1 & 2 & 3 & 4 & 5 & 6 & 7 & 8 & 9\end{array}$

3) To what degree did you feel positively toward the debater? 


$\begin{array}{llllllllll}1 & 2 & 3 & 4 & 5 & 6 & 7 & 8 & 9\end{array}$

\section{Intent to Vote}

Please indicate with the following statements what you think about the debater you just saw.

1) How likely are you to vote for this debater in the next election?

Very likely-

$\begin{array}{lllllllll}1 & 2 & 3 & 4 & 5 & 6 & 7 & 8 & 9\end{array}$

Very unlikely

9

2) What are the chances of you voting for this debater in the next election?

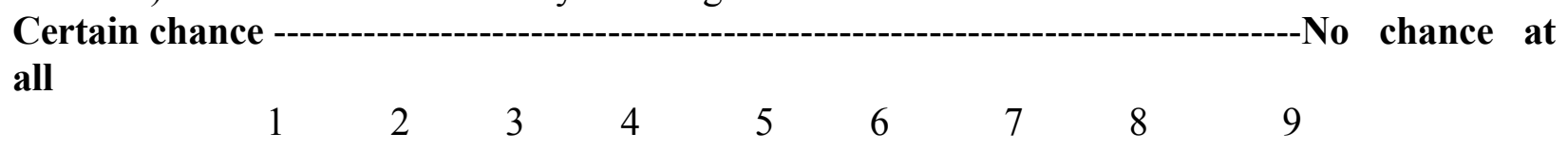

3) How likely are you to tell your friends or family to vote for this debater?

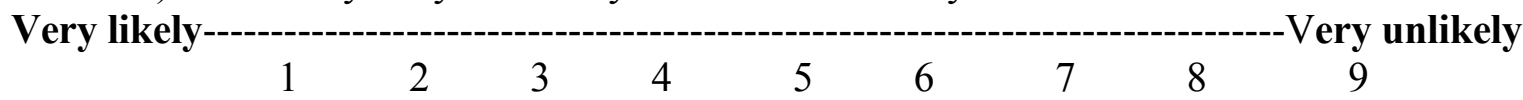

\section{$\underline{\text { Demographic Questions }}$}

Please complete the following demographic questions. Keep in mind your answers are strictly confidential and will be shared with anyone outside of this study.

1. Age today: years

2. Gender: Male or Female

3. Please choose one category that best described your ethnicity:
- African American
- Asian
- Caucasian
- Arabic/Indian
- Native American
- Hispanic
- North American Indian
- Pacific Islander
O Other (please specify)

4. What is your current year in college?

- Freshman

- Sophomore 
○ Junior

- Senior

- Graduate Student

5. Indicate your major here:

5. How would you describe your political affiliations?

- Strongly Republican

- Republican

- Moderate

- Democratic

- Strongly Democratic

$\circ$ Other (please specify)

6. How would you describe your parents' political affiliations?

- Strongly Republican

- Republican

- Moderate

- Democratic

- Strongly Democratic

o Other (please specify)

7. Is English your primary language?

- No

- Yes

8. Please estimate your parents' totally household income before taxes:

- Less than $\$ 20,000$

- $\$ 20,001$ to $\$ 40,000$

- $\$ 40,001$ to $\$ 60,000$

- $\$ 60,001$ to $\$ 80,000$

- $\$ 80,001$ to $\$ 100,000$

- $\$ 100,001$ to $\$ 120,000$

○ $\$ 120,001$ to $\$ 140,000$

- More than $\$ 140,001$ 